OPEN ACCESS

International Journal of

Environmental Research and

Public Health

ISSN 1660-4601

www.mdpi.com/journal/ijerph

Article

\title{
A Low-Cost Wheat Bran Medium for Biodegradation of the Benzidine-Based Carcinogenic Dye Trypan Blue Using a Microbial Consortium
}

\author{
Harshad Lade ${ }^{1}$, Avinash Kadam ${ }^{2}$, Diby Paul ${ }^{1, *}$ and Sanjay Govindwar ${ }^{3, *}$ \\ 1 Department of Environmental Engineering, Konkuk University, Seoul 143-701, Korea; \\ E-Mail: harshadlade@gmail.com \\ 2 Department of Environmental Engineering, Kyungpook National University, Daegu 702-701, \\ Korea; E-Mail: avikadam2010@gmail.com \\ 3 Department of Biochemistry, Shivaji University Kolhapur 416004, India \\ * Authors to whom correspondence should be addressed; E-Mails: dibypaul@live.com (D.P.); \\ spg_biochem@unishivaji.ac.in (S.G.); Tel.: +82-2450-3318 (D.P.); +91-231-260-9152 (S.G.); \\ Fax: +82-2450-3542 (D.P.); +91-231-2691-533 (S.G.).
}

Academic Editor: Oladele A. Ogunseitan

Received: 2 March 2015 / Accepted: 19 March 2015 / Published: 25 March 2015

\begin{abstract}
Environmental release of benzidine-based dyes is a matter of health concern. Here, a microbial consortium was enriched from textile dye contaminated soils and investigated for biodegradation of the carcinogenic benzidine-based dye Trypan Blue using wheat bran (WB) as growth medium. The PCR-DGGE analysis of enriched microbial consortium revealed the presence of 15 different bacteria. Decolorization studies suggested that the microbial consortium has high metabolic activity towards Trypan Blue as complete removal of $50 \mathrm{mg} \cdot \mathrm{L}^{-1}$ dye was observed within $24 \mathrm{~h}$ at $30 \pm 0.2{ }^{\circ} \mathrm{C}$ and $\mathrm{pH} 7$. Significant reduction in TOC (64\%) and COD (88\%) of dye decolorized broths confirmed mineralization. Induction in azoreductase $(500 \%)$, NADH-DCIP reductase $(264 \%)$ and laccase $(275 \%)$ proved enzymatic decolorization of dye. HPLC analysis of dye decolorized products showed the formation of six metabolites while the FTIR spectrum indicated removal of diazo bonds at 1612.30 and $1581.34 \mathrm{~cm}^{-1}$. The proposed dye degradation pathway based on GC-MS and enzyme analysis suggested the formation of two low molecular weight intermediates. Phytotoxicity and acute toxicity studies revealed the less toxic nature of the dye degradation products. These results provide experimental evidence
\end{abstract}


for the utilization of agricultural waste as a novel low-cost growth medium for biodegradation of benzidine-based dyes, and suggested the potential of the microbial consortium in detoxification.

Keywords: wheat bran; benzidine-based dyes; Trypan Blue; mutagenic; microbial consortium; decolorization; biodegradation; detoxification.

\section{Introduction}

The U.S. Environmental Protection Agency (EPA) has identified an initial list of widely recognized benzidine-based and benzidine congener-based dyes for action plan development due to their human toxicity, recalcitrance and bioaccumulative characteristics [1]. There is a well-established concern for the potential human carcinogenic effects presented by exposure to benzidine-based dyes [1]. These dyes get broken down to certain aromatic amines of concern such as benzidines, which are known as possible carcinogens or genotoxicants [2]. It is well-known that benzidine and its congeners react with DNA which results in mutations [3]. There are many reports on the mutagenicity of benzidine-based dyes and their congeners [4-6]. In addition, their degradation metabolites, e.g. aromatic amines, are reported as toxic, mutagenic as well as carcinogenic, which may pose additional health hazards to humans $[7,8]$.

Benzidine-based and congener-based dyes are widely used in the production of textiles, paints, printing inks, leather colorings, paper making, pharmaceuticals and food industries [1]. The excessive use of such dyes at industrial levels leads to their release to the environment through waste disposal and thus may contaminate river waters, sediments, sludges and drinking waters. A systematic backtracking of the flow of wastewater from textile processing industries within the European Union has identified several benzidine-based mutagenic dyes in exposed sites [9]. Some of such dyes as well as their degradation metabolites may pass through the food chain from soil or water and lead to serious ecological and human health effects. Examples of benzidine-based dyes include the blue acidic azo dye Trypan Blue, which is extensively used in the textile, food and paint industries for dyeing silk, cotton, wool, nylon and also for coloring oil, waxes, varnish, plastics, etc. Release of Trypan Blue in the environment creates serious human health problems as it is known for its enhanced mutagenicity and high recalcitrance towards microbial degradation because of its fused aromatic ring structure [10]. Trypan Blue has been reported as carcinogenic in rats and its administration produced reticulum-cell sarcomas of the liver and fibrosarcomas at the site of injection [11]. Thus, there is a significant interest in developing effective treatment technologies for the complete removal of benzidine-based dyes from environmental sinks as their discharge poses mutagenic and/or carcinogenic risks to mammals and/or humans.

Removal of dyes from environmental sinks can be achieved through different physicochemical and biological processes. The physicochemical methods applied include membrane separations, photocatalysis, sonication, irradiation, photochemical process, electrochemical oxidation, ion exchange, activated carbon adsorption, coagulation/flocculation, ozonation and Fenton processes [12-14]. A widely used commercial chemical method of dye removal is coagulation which rapidly transfers dyes from the 
liquid to the solid phase but has several drawbacks such the inability to remove dyes completely, the high cost of the chemicals used, generation of hazardous secondary wastes and its disposal problem [15,16]. Another physical method like adsorption on low cost adsorbents like fly ash, activated carbon and/or agricultural waste is an inexpensive and commonly used process for removal of dyes from industrial wastewaters; but the release of adsorbed dyes is a major issue of concern as these remain in the environment for long time [13,17]. Advanced oxidation processes generate the second most powerful oxidant, the $\mathrm{OH}$ free radical, to oxidize dyes ultimately to $\mathrm{CO}_{2}$ and $\mathrm{H}_{2} \mathrm{O}$, but these processes are also not sufficient to completely remove dyes and are known to generate secondary wastes which are reported as toxic or even more harmful than the parent dyes [16,18-20]. Overall, each physicochemical method has its own advantages and drawbacks. It is thus necessary to use an alternative eco-friendly and cost effective treatment method which can remove the dyes as well as detoxify them. Thus, bioremediation has been suggested as a promising method which not only potentially mineralizes dye molecules into $\mathrm{CO}_{2}$ and $\mathrm{H}_{2} \mathrm{O}$, but also generates low amounts of sludge [21].

Over the past decade, several bacteria, fungi, algae, lichen, plants as well as their consortia have been shown able to degrade structurally different hazardous dyes [22-28]. Among these promising biological systems, bacteria have attracted the attention of the scientific community because of their short life cycle, less secondary pollution and the fact they can grow on various substrates. Indeed, most research to date has been conducted by using defined growth media such as nutrient broth for cultivating bacteria, which is not affordable to use at commercial levels. Therefore, research is needed to find alternative carbon- and nitrogen-containing substrates that can support bacterial growth and are also easily available at low cost. The possible use of agricultural waste as a low cost carbon and nitrogen source should not be neglected. Several crop biomass such as rice bran, sugarcane bagasse, wheat bran, etc. are generated every year in million ton amounts as "agricultural waste", easily available at low cost and they are known to contain high amounts of carbon and nitrogen $[29,30]$. Recently, agricultural waste rice bran, yeast biomass and sugarcane bagasse were reported as promising growth media for the removal of dyes from textile wastewaters in solid state fermentation (SSF) processes [30-32]. However, at present submerged fermentation technology has well-developed protocols for wastewater treatments, while at the same time SSF is at the development stage for field level applications [33]. Hence it is quite beneficial to use submerged fermentation conditions for wastewater treatment using agricultural wastes as growth medium. As a representative of agricultural waste, wheat bran (WB) was evaluated as a growth medium in this study because it is available at low cost and contains a combination of carbohydrates, proteins, amino acids and trace elements [34]. In addition, WB has been reported to be good a growth medium for carboxymethyl cellulose production by Aspergillus flavus, cellulose production by Paenibacillus terrae ME27-1 and hydrolytic enzymes production by Bacillus megatherium [34-36].

The overall aim of this research was therefore to enrich a microbial consortium having the ability to degrade and completely detoxify the benzidine-based carcinogenic dye Trypan Blue using agricultural waste WB as growth medium, to provide further understanding of the mechanisms involved in dye mineralization and also to indicate possible applicationa of agricultural waste as a low cost growth medium for bioremediation of hazardous dyes. In this work, a microbial consortium from dye contaminated soils.capable of decolorizing the benzidine-based dye Trypan Blue was enriched in WB 
medium. The bacterial diversity of the enriched consortium was investigated by PCR-DGGE analysis. The decolorization experiments were performed using wheat bran as growth medium under submerged fermentation conditions. Mineralization of the dye was determined by the reduction in TOC and COD values while the role of oxidoreductive enzymes in the biotransformation process was analyzed by standard assays. Degradation of the dye and formation of metabolites was confirmed by HPLC, FTIR and GC-MS analysis. Additionally, a possible pathway for the degradation of Trypan Blue dye by the microbial consortium was proposed based on the enzyme activities and analytical studies. Detoxification of dye degraded products was assessed by phytotoxicity and acute toxicity tests.

\section{Materials and Methods}

\subsection{Chemicals and Dye Used}

2,2'-Azino-bis (3-ethylbenzothiazoline-6-sulfonic acid) (ABTS), veratryl alcohol, catechol, veratryl alcohol, methyl red, nicotinamide adenine dinucleotide (NADH) and dichlorophenol indophenols (DCIP) were procured from HiMedia Laboratories Pvt. Ltd. (Mumbai, India). Chloranil, dimethylformamide (DMF), aniline-2-sulfonic acid and all other chemicals were obtained from Sigma-Aldrich (St. Louis, MO, USA). All the chemicals used in this study were of high purity ( $>98 \%)$. Trypan Blue (CAS No. 72-57-1; CI No. 23850; CI Name = Direct Blue 14; Molecular Formula $=\mathrm{C}_{34} \mathrm{H}_{24} \mathrm{~N}_{6} \mathrm{O}_{14} \mathrm{~S}_{4} \mathrm{Na}_{4}$; Molecular Weight $=960.81 \mathrm{~g} \cdot \mathrm{mol}^{-1} ; \lambda \max 660 \mathrm{~nm}$ ); $\lambda \max 660 \mathrm{~nm}$ ), a water-soluble azo dye was procured from Sigma-Aldrich and used as received. Its chemical structure is shown in Figure 1. Unless otherwise stated, the working concentration of dye Trypan Blue was $50 \mathrm{mg} \cdot \mathrm{L}^{-1}$.<smiles>Cc1cc(-c2ccc(/N=N/c3c(S(=O)(=O)O[Na])cc4cc(S(=O)(=O)O[Na])cc(N)c4c3O)c(C)c2)ccc1/N=N/c1c(S(=O)(=O)O[Na])cc2cc(S(=O)(=O)O[Na])cc(N)c2c1O</smiles>

Figure 1. Structure of the benzidine-based azo dye Trypan Blue.

\subsection{Wheat Bran Medium}

Agricultural waste wheat bran was obtained from a local wholesalers shop at Kolhapur (MS, India). It was passed through 50 -mesh sieve and dried in an oven at $80{ }^{\circ} \mathrm{C} \pm 1{ }^{\circ} \mathrm{C}$ until the weight was constant. For decolorization studies, five gram of dried wheat bran was boiled in $100 \mathrm{~mL}$ of distilled water for 15 minutes and the extract was separated by filtration through Whatman grade no. 1 filter paper. The resulting clear filtrate was then made up to a total volume of $100 \mathrm{~mL}$ with distilled water, the $\mathrm{pH}$ was adjusted to 7.0 , it was autoclaved for $15 \mathrm{~min}$ at $121{ }^{\circ} \mathrm{C}$ and used as $\mathrm{WB}$ medium. Total sugars content in the WB medium was estimated by the anthrone method using glucose as a standard [37]; while protein concentration was quantified by Lowry's method with bovine serum albumin as a standard [38]. 


\subsection{Enrichment of the Trypan Blue Decolorizing Microbial Consortium}

A soil sample of approximately $100.0 \mathrm{gm}$ was collected from the surface layer $(5-10 \mathrm{~cm})$ of dye contaminated areas at Mahesh Textile Processers (Ichalkarangi, Maharashtra, India). The sample was packed in an air tight polythene re-sealable bag, kept in an ice box, transported to laboratory and stored in a refrigerator for further use. The microbial consortium capable of decolorizing Trypan Blue dye was enriched by inoculating $1.0 \mathrm{gm}$ of dye contaminated soils in a $250 \mathrm{~mL}$ Erlenmeyer flask containing $100 \mathrm{~mL}$ of WB medium supplemented with $25 \mathrm{mg} \cdot \mathrm{L}^{-1}$ of dye. The inoculated flask was allowed to enrich under microaerophilic incubation conditions (i.e. no aeration and agitation) at $30 \pm 0.2{ }^{\circ} \mathrm{C}$ for a week and further acclimatized consecutively until it showed complete decolorization of dye under the same conditions. The developed consortium was then cultured in WB medium containing $25 \mathrm{mg} \cdot \mathrm{L}^{-1}$ of dye Trypan Blue to retain its decolorization activity and stored at $4 \pm 1{ }^{\circ} \mathrm{C}$ for two months use and in glycerol $(20 \%, \mathrm{v} / \mathrm{v})$ at $-80 \pm 1^{\circ} \mathrm{C}$ for long term use.

\subsection{Microbial Diversity Analysis}

The polymerase chain reaction-denaturing gradient gel electrophoresis (PCR-DGGE) technique was applied to investigate the bacterial diversity present in the developed microbial consortium. Initially, the consortium was grown in WB medium for $24 \mathrm{~h}$ at $30 \pm 0.2{ }^{\circ} \mathrm{C}$ under microaerophilic conditions. In addition, it was also grown in the presence of the dye Trypan Blue $\left(50 \mathrm{mg} \cdot \mathrm{L}^{-1}\right)$ to investigate the changes in bacterial community after dye exposure. The genomic DNA from enriched cultures was extracted as previously described and subjected to PCR amplification of 16S rRNA genes [39].

PCR amplification was performed using the forward primer RDB1-GC clamped (F58 CGCCGCC GCGCCCCGCGCCCGGCCCGCCGCCGCGGCCGCAGTTTGATCCTGGCTCA) and reverse primer RDB2 (GGACTACCAGGGTATCTAAT). The PCR reaction mixture contained a total volume of $50 \mu \mathrm{L}$ having $1 \times$ PCR buffer, $1 \mathrm{nM}$ of dNTPs, 1 unit Taq DNA polymerase, $2 \mathrm{mM} \mathrm{MgSO}_{4}, 2 \mu \mathrm{L}$ of template DNA and $0.25 \mathrm{pM}$ of forward and reverse primers [13]. The temperature cycling conditions were as follows: initial denaturation for $5 \mathrm{~min}$ at $95{ }^{\circ} \mathrm{C}$ followed by 35 cycles of $15 \mathrm{~s}$ at $95{ }^{\circ} \mathrm{C}, 15 \mathrm{~s}$ at $50{ }^{\circ} \mathrm{C}$, and $15 \mathrm{~s}$ at $72{ }^{\circ} \mathrm{C}$ followed by $10 \mathrm{~min}$ final extension at $72{ }^{\circ} \mathrm{C}$. The amplified products were purified by PureLink PCR purification kit (Invitrogen, Bedford, MA, USA).

DGGE analysis was performed using a D-Code System (Bio-Rad Laboratories, Singapore) maintained at a constant temperature of $60{ }^{\circ} \mathrm{C}$ in $1 \mathrm{x}$ TAE buffer. PCR amplicons were loaded onto $8 \%$ (w/v) polyacrylamide gels (37.5:1, acrylamide/bisacrylamide) using a denaturing gradient ranging from $30 \%$ to $55 \%$ denaturant $(100 \%$ denaturant is defined as $7 \mathrm{M}$ urea and $40 \%(\mathrm{v} / \mathrm{v})$ formamide). The electrophoresis was run at $75 \mathrm{~V}$ for $16 \mathrm{~h}$, stained with silver nitrate and visualized [13,40]. Silver stained DGGE gel images were captured using Uvitec Gel Doc system (UVitec Ltd., Cambridge, UK).

\subsection{Pre-enrichment of the Microbial Consortium}

The developed microbial consortium stock culture was routinely pre-enrichment in WB medium. One hundred $\mu \mathrm{L}$ of $48 \mathrm{~h}$ old microbial consortium culture was inoculated in a $250 \mathrm{~mL}$ Erlenmeyer flask containing $100 \mathrm{~mL} \mathrm{WB}$ medium and incubated at $30 \pm 0.2{ }^{\circ} \mathrm{C}$ for $24 \mathrm{~h}$ under shaking condition (120 rpm). This overnight-grown culture was then used as inoculum for further dye degradation 
studies. Unless otherwise specified, these pre-enrichment conditions were maintained throughout the experiments.

\subsection{Decolorization Studies}

All decolorization experiments were performed in $250 \mathrm{~mL}$ Erlenmeyer flasks containing $100 \mathrm{~mL}$ of pre-enriched microbial consortium. Initially, $50 \mathrm{mg} \cdot \mathrm{L}^{-1}$ of Trypan Blue dye was added into the pre-enriched culture flaks and kept under microaerophilic and aerobic (shaking at $120 \mathrm{rpm}$ ) incubation conditions at $30{ }^{\circ} \mathrm{C} \pm 0.2{ }^{\circ} \mathrm{C}$. Aliquots of $2 \mathrm{~mL}$ were withdrawn from the experimental and control media at regular intervals of $8 \mathrm{~h}$ till $24 \mathrm{~h}$ and the cell mass was harvested by adding an equal volume of ethyl acetate followed by centrifugation $\left(7500 \times \mathrm{g}\right.$ for $\left.20 \mathrm{~min}, 4 \pm 0.2^{\circ} \mathrm{C}\right)$ to obtain a clear supernatant. Decolorization of the dye Trypan Blue was measured spectrophotometrically at a $\lambda_{\max }$ of $660 \mathrm{~nm}$ (U-2800 UV-vis spectrophotometer, Hitachi, Tokyo, Japan). Pre-enriched microbial consortium culture without dye was considered as the biotic control and tested under the same conditions. Uninoculated medium containing $50 \mathrm{mg} \cdot \mathrm{L}^{-1}$ of dye served as the abiotic control. Unless otherwise specified, all the experiments were performed in three sets. The percent decolorization was calculated using the formula:

$$
{\text { Decolorization }(\%)=\frac{\text { Initial absorbance }_{(0 \mathrm{~h})}-\text { Observed absorbance after incubation }_{(\mathrm{t})}}{\text { Initial }_{\text {absorbance }}} \times 100}_{(0 \mathrm{~h})}
$$

\subsection{Optimization of Decolorization Parameters}

In order to develop an efficient decolorization process, the optimization of various environmental parameters was carried out by a one parameter at a time approach in WB medium [27]. This includes initial $\mathrm{pH}$ of the pre-enriched culture medium (5-10), incubation temperature $(20,30,37,40$ and $\left.50 \pm 0.2^{\circ} \mathrm{C}\right)$ and various dye concentration $\left(25-100 \mathrm{mg} \cdot \mathrm{L}^{-1}\right)$.

\subsection{Determination of Aromatic Amines, TOC and COD}

The aromatic amines formed during decolorization process were estimated spectrophotometrically as described earlier [41]. Aliquots of $2 \mathrm{~mL}$ were withdrawn from the experimental and control media at regular intervals of $8 \mathrm{~h}$ and freeze-dried in an Upright Freeze Dryer (FDU5003/8603, Operon Co. Ltd., Seoul, Republic of Korea). Five milligrams of freeze-dried samples were dissolved in $5 \mathrm{~mL}$ of a $0.4 \%$ chloranil solution in DMF, heated at $100 \pm 1{ }^{\circ} \mathrm{C}$ for $5 \mathrm{~min}$ and absorbance was measured at $560 \mathrm{~nm}$. A calibration curve of aniline-2-sulfonic acid as a model amine product of azo dyes reduction was prepared. The concentration of amines formed in sample were calculated from standard curve and mentioned in $\mathrm{mM}$.

Dye mineralization was confirmed by analyzing the total organic carbon (TOC) and chemical oxygen demand (COD) of treated dye medium. TOC was estimated using an automated TOC analyzer (Hach DR 2700 spectrophotometer, Hach Co., Loveland, CO, USA), while the COD was measured according to standard methods [42]. For this, experimental and control medium were taken, centrifuged $\left(7500 \times \mathrm{g}\right.$ for $\left.15 \mathrm{~min}, 4 \pm 0.2{ }^{\circ} \mathrm{C}\right)$, supernatant collected, passed through $0.45 \mu \mathrm{m}$ pore size 
filter to remove bacterial cell debris and analyzed. The removal ratio of TOC was calculated using the formula:

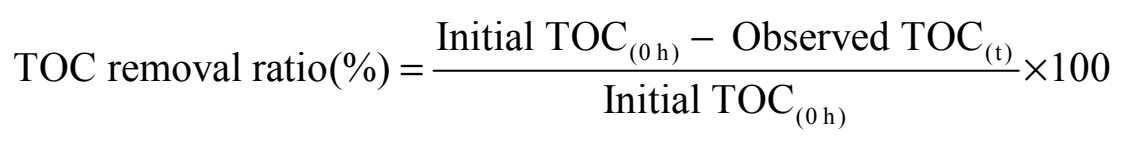

where, $\left.\operatorname{TOC}_{(0} \mathrm{h}\right)$ and $\operatorname{TOC}_{(\mathrm{t})}$ are the initial TOC value at $(0 \mathrm{~h})$ and the TOC value after particular decolorization time $(\mathrm{t})$, respectively.

\subsection{Enzyme Studies}

Microbial consortium was grown in WB medium amended with Trypan Blue $\left(50 \mathrm{mg} \cdot \mathrm{L}^{-1}\right)$ at $30 \pm 0.2{ }^{\circ} \mathrm{C}$ for $24 \mathrm{~h}$. Cell biomass was harvested by centrifugation $\left(7500 \times g\right.$ for $\left.15 \mathrm{~min}, 4 \pm 0.2^{\circ} \mathrm{C}\right)$. The harvested cells were suspended in potassium phosphate buffer $(50 \mathrm{mM}, \mathrm{pH} 7.4)$ and lysed using Sonics-vibracell VCX130 ultrasonic cell distrupter (Sonics \& Materials Inc., Newtown, CT, USA) while maintained at $4 \pm 0.2{ }^{\circ} \mathrm{C}$ keeping sonifier output at $40 \%$ amplitude and seven strokes each of $30 \mathrm{~s}$ with $2 \mathrm{~min}$ rest. The processed homogenate was again centrifuged and supernatant was used as source of crude enzymes. Similar procedures were followed for extraction of enzymes from control medium.

Activities of oxidative enzymes laccase, tyrosinase and veratryl alcohol oxidase as well as reductive enzymes azoreductase and ADH-DCIP reductase were assayed using a UV-vis spectrophotometer. Laccase activity was estimated by monitoring the increase in optical density at $420 \mathrm{~nm}$ $\left(\Sigma 420 \mathrm{~nm}=36,000(\mathrm{M} \cdot \mathrm{cm})^{-1}\right)$ due to the oxidation of ABTS in $0.1 \mathrm{M}$ acetate buffer ( $\left.\mathrm{pH} 4.9\right)$ [43]. Tyrosinase activity was measured at $495 \mathrm{~nm}$ using the method described by Zhang and Flurkey [44]. Veratryl alcohol oxidase activity was determined by monitoring the formation of veratraldehyde at $310 \mathrm{~nm}\left(\Sigma 310 \mathrm{~nm}=9300(\mathrm{M} \cdot \mathrm{cm})^{-1}\right.$ [45]. Azoreductase activity was measured by monitoring the reduction in concentration of Methyl Red at $430 \mathrm{~nm}\left(\sum 430 \mathrm{~nm}=23,360(\mathrm{M} \cdot \mathrm{cm})^{-1}\right)$ [46]. NADPH-DCIP reductase activity was determined at $590 \mathrm{~nm}\left(19 \mathrm{mM}^{-1} \cdot \mathrm{cm}^{-1}\right)$ using a procedure reported earlier [47]. Proteins were determined by Lowry et al. method with bovine serum albumin as standard [38]. All assays were performed under ambient conditions and in triplicates.

\subsection{Biodegradation Studies}

Extraction of metabolites after decolorization of Trypan Blue $\left(50 \mathrm{mg} \cdot \mathrm{L}^{-1}\right)$ by the microbial consortium was carried out as described earlier with some modifications [48]. Briefly, $100 \mathrm{~mL}$ of sample was taken and harvested by centrifugation $\left(10,000 \times \mathrm{g}\right.$ for $\left.20 \mathrm{~min}, 4 \pm 0.2{ }^{\circ} \mathrm{C}\right)$ to obtain cell-free supernatant. Equal volume of ethyl acetate was added into the supernatant, mixed vigorously, organic layer separated and dried in a SpeedVac (Thermo Fisher Scientific Inc., Waltham, MA, USA). These remained metabolites were dissolved in $3 \mathrm{~mL}$ methanol, passed through a $0.45 \mu \mathrm{m}$ cellulose acetate filter, reduced to $250 \mu \mathrm{L}$ by evaporation and used for HPLC, FTIR and GC-MS analysis.

High performance liquid chromatography (HPLC) was performed on an Agilent 1200 HPLC system (Agilent, Santa Clara, CA, USA) equipped with a ZORBAX Eclipse XDB-C18 column (4.6 mm $\times$ $150 \mathrm{~mm}, 5 \mu \mathrm{m}$ particle size) kept at $25^{\circ} \mathrm{C}$. Five $\mu \mathrm{L}$ of dye and its decolorized extract were injected into the column. The elution was carried out using isocratic mobile phase of acetonitrile-methanol 
(60:40) with a flow rate of $0.5 \mathrm{~mL} \mathrm{m^{-1 }}$ for 20 min while the UV detector was set at $210 \mathrm{~nm}$. Fourier transform infrared spectra (FTIR) of the dye and its decolorized extract were collected using a Spectrum One spectrometer in the mid IR region of 400-4000 $\mathrm{cm}^{-1}$ with 16 scan speed (PerkinElmer, Branford, CT, USA). The samples were mixed with ACS reagent grade potassium bromide (5:95), pellets were made, fixed in sample holder and analyzed. Gas chromatography coupled with mass spectroscopy (GC-MS) analysis of metabolites was performed using a QP2010 instrument (Shimadzu Corporation, Kyoto, Japan) as mentioned previously with some modifications [49]. Gas chromatography was performed in temperature programming mode with Resteck column $(0.25 \mathrm{~mm} \times$ $30 \mathrm{~m}$ long) while ionization voltage set at $70 \mathrm{eV}$. The initial column temperature was maintained at $40{ }^{\circ} \mathrm{C}$ for 4 min and increased linearly at $10{ }^{\circ} \mathrm{C}$ per min to $290{ }^{\circ} \mathrm{C}$ and held for $4 \mathrm{~min}$. Injection port temperature was $250{ }^{\circ} \mathrm{C}$ and mass interface was maintained at $220^{\circ} \mathrm{C}$. Helium was used as carrier gas at a flow rate of $1 \mathrm{~mL} \mathrm{~min}^{-1}$ for $30 \mathrm{~min}$ run time. Intermediates were identified on the basis of their mass spectra and NIST library data [50].

\subsection{Toxicity Studies}

Risk assessment of the dye Trypan Blue and its ethyl acetate extracted degradation products was performed by phytotoxicity and acute toxicity assays. The phytotoxicity test was performed at room temperature on two kinds of agriculturally important crops: Sorghum vulgare (monocot) and Phaseolus mungo (dicot) as mentioned earlier [27]. Ten seeds of each crop were daily irrigated with 10 $\mathrm{mL}$ each of Trypan Blue $\left(50 \mathrm{mg} \cdot \mathrm{L}^{-1}\right)$, its degradation metabolites $\left(50 \mathrm{mg} \cdot \mathrm{L}^{-1}\right)$ and distilled water as control. After 13 days, the length of shoot, root and seed germination was recorded. The percent of germination was calculated using the formula:

$$
\text { Germination }(\%)=\frac{\text { No. of seeds germinated }}{\text { No. of seeds sowed }} \times 100
$$

Acute toxicity was determined on the freshwater organism Daphnia magna as described previously [51,52]. The Trypan Blue dye $\left(50 \mathrm{mg} \cdot \mathrm{L}^{-1}\right)$ medium decolorized using the microbial consortium was centrifuged $\left(7500 \times g\right.$ for $\left.20 \mathrm{~min}, 4 \pm 0.2{ }^{\circ} \mathrm{C}\right)$, the supernatant was separated and sterilized by passing through a $0.45 \mu \mathrm{m}$ pore size filter. The resulting clear filtrate was then used to perform sensitivity tests using $24 \mathrm{~h}$ old neonates. The assay was initiated by adding five neonates into each Erlenmeyer flask containing $25 \%, 50 \%, 75 \%, 100 \%$ dilution of filtrate. The flasks were kept at $20 \pm 0.2{ }^{\circ} \mathrm{C}$ for $48 \mathrm{~h}$ in the absence of light and numbers of immobile organisms were counted after exposing to light for 20 seconds. Assay was performed in triplicate with distilled water as control.

\subsection{Data Analysis}

All the results reported are means of three replicates. Basic statistical analyses were performed using the software SPSS 17.0 (SPSS, Chicago, IL, USA). Significance was analyzed using an ANOVA with Tukey-Kramer multiple comparison test. 


\section{Results and Discussion}

\subsection{Microbial Diversity Analysis}

PCR-DGGE, a well-established fingerprinting technique, was used to investigate the bacterial diversity of the enriched consortium, which provided meaningful information on changes in the bacterial community composition after decolorization of the dye. This technique separates the PCR amplified DNA of the same size but different sequences and thus each band obtained on a gel indicates the presence of an individual bacterium. PCR-DGGE was recently introduced in the field of molecular microbial ecology to analyze the diversity of bacterial populations [53,54]. In present study, the primary aim of the bacterial diversity analysis was to check the ability of the bacteria making up the enriched consortium to tolerate the dye Trypan Blue. Result of the DGGE analysis showed 15 distinctive bands suggesting the presence of 15 different bacteria in the enriched consortium (Figure 2a).

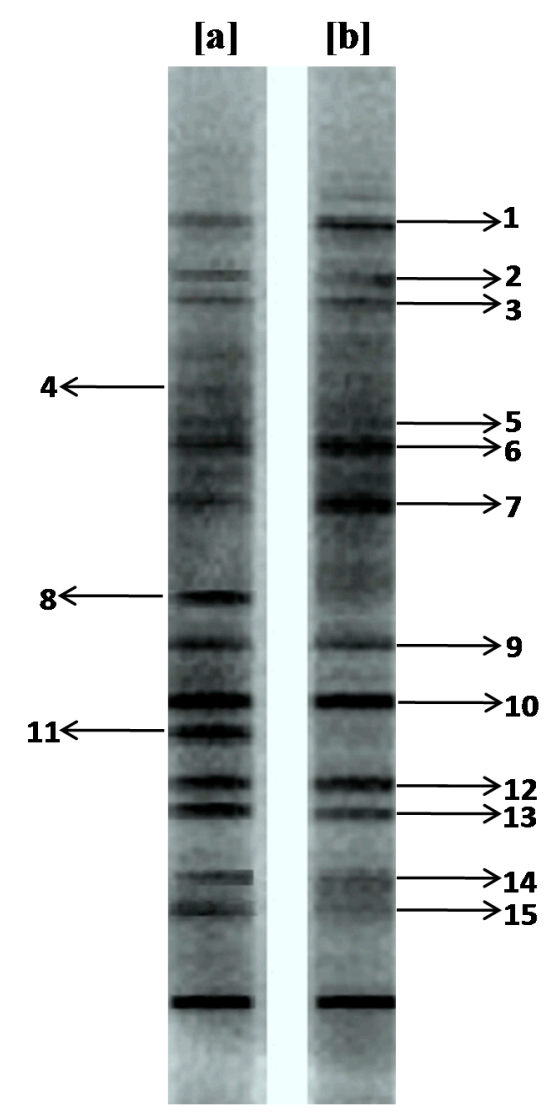

Figure 2. DGGE pattern of the PCR amplified 16S rDNA genes of enriched microbial consortium (a) before and (b) after decolorization of dye Trypan Blue $\left(50 \mathrm{mg} \cdot \mathrm{L}^{-1}\right)$.

However, the microbial diversity analysis after exposure to the dye Trypan Blue at $50 \mathrm{mg} \cdot \mathrm{L}^{-1}$ concentration revealed that some bands such as $1,2,3,5,6,7,9,10,12,13,14$ and 15 seemed to be stable in dye decolorized broth while other bands like 4, 8 and 11 detected in the enriched microbial consortium disappeared (Figure 2b). Moreover, compared with the bands in the enriched microbial consortium before use for dye decolorization, some bands such as 1, 6 and 7 became more pronounced 
in the dye decolorized broth. Similar observations were reported by Joshi et al. [40], where exposure of a soil bacterial population to the diazo dye Congo Red affected its community structure. As shown in Figure 2, the dye decolorized broth had a very similar bacterial community as the original enriched microbial consortium. These observations implied that most of the bacteria present in the enriched consortium have a significant ability to tolerate and/or degrade the dye Trypan Blue at $50 \mathrm{mg} \cdot \mathrm{L}^{-1}$ concentration. This might be due to the higher presence of textile dyestuffs in the collected soils based on the fact that continuous dyestuff amendment could enhance the microbial ability to tolerate and/or degrade dyes.

\subsection{Decolorization of Trypan Blue}

Agricultural wastes are inexhaustible, non-hazardous, easily available and considered as an alternative source of nutrients to defined microbial growth media. Several agricultural wastes including rice bran, yeast biomass and sugarcane bagasse have been used previously as growth substrates for biodegradation of hazardous dyes in SSF processes [30-32]. In addition, wheat bran a widely available agricultural residue has been reported as a growth medium for low cost production of industrially important enzymes, but ignored in dyes degradation studies [36]. Thus, there is great possibility to use wheat bran as growth medium for the biodegradation of hazardous dyes and make the process cost effective. In the present study, wheat bran was pretreated for extraction of carbon and nitrogen sources so as to make a growth medium for bacterial cultivation and further degradation of dyes. The biochemical analysis of WB medium showed $118 \mathrm{mg}$ of protein and $486 \mathrm{mg}$ of total sugars. Wheat bran has been reported to contain good amounts of carbohydrates, proteins, amino acids and elements [34]. Initially, submerged culture studies on decolorization of the dye Trypan Blue $\left(50 \mathrm{mg} \cdot \mathrm{L}^{-1}\right)$ by the microbial consortium were performed in WB medium under microaerophilic conditions. UV-Vis spectrophotometric analysis of the dye and its decolorized products indicate a high decrease in the absorbance for the microbial consortium-treated medium within $24 \mathrm{~h}$, suggesting dye decolorization (Figure 3 ). This preliminary result suggests that low cost wheat bran could be used as a growth medium for the decolorization of benzidine-based dyes. Decolorization of Trypan Blue by the self-immobilizing fungal biomass of Pycnoporus sanguineus has been previously reported in defined glucose-yeast extract-malt extract-peptone medium [55]. Moreover, an individual culture of thermophilic fungus, Thermomucor indicae-seudaticae was shown to degrade an azo-anthraquinone dye mixture containing Trypan Blue within 6 days in potato dextrose broth [56]. However, biodegradation by a single culture is known to take longer time, require defined media for growth, degrade particular dyes only and to also lead to the formation of toxic aromatic amines; while biodegradation by consortium cultures occurs faster without producing toxic amines and they also possess higher dye concentration tolerance [27]. Additionally, Trypan Blue is known to be a sturdy dye with high recalcitrance towards biological degradation [56]. Hence, to overcome the limitations of single culture, a microbial consortium consisting of 15 distinctive bacteria as determined by DGGE analysis has been investigated for the degradation and detoxification of the diazo dye Trypan Blue in present study. 


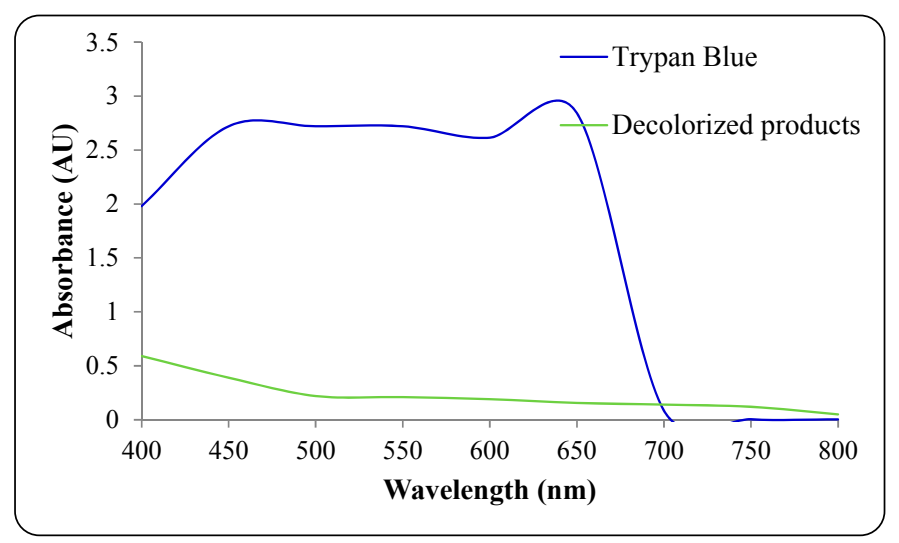

Figure 3. UV-visible overlay spectra of dye Trypan Blue and its ethyl acetate extracted decolorized products after $24 \mathrm{~h}$ treatment with microbial consortium.

Molecular oxygen is known to play an important role in the decolorization of dyes. This perception is been well supported in the present work, as aerobic incubation has an inhibitory effect on Trypan Blue decolorization whereby only $12 \%$ dye removal was observed within $24 \mathrm{~h}$ (Figure 4 ). On the contrary, almost $99 \%$ decolorization was observed in $24 \mathrm{~h}$ under microaerophilic conditions.

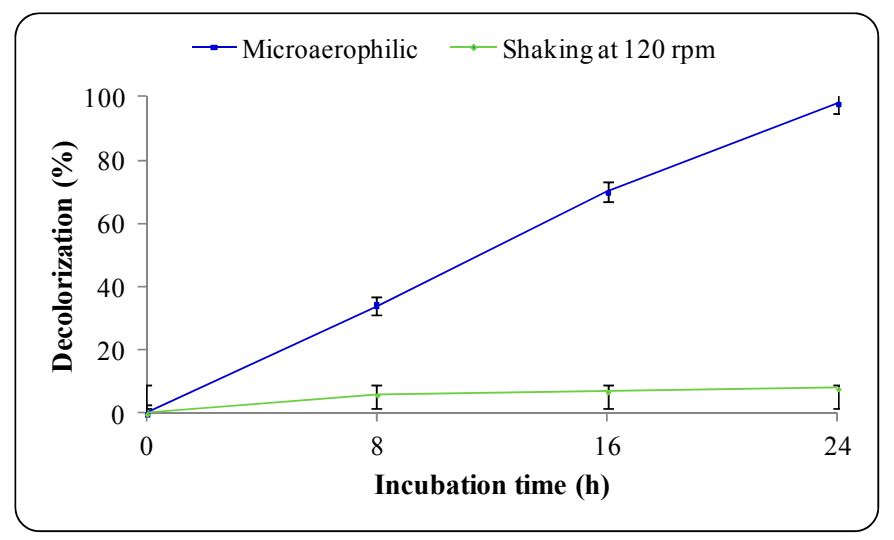

Figure 4. Effect of microaerophilic and aerobic (shaking at $120 \mathrm{rpm}$ ) conditions on decolorization of dye Trypan Blue $\left(50 \mathrm{mg} \cdot \mathrm{L}^{-1}\right)$ by microbial consortium at $30 \pm 0.2{ }^{\circ} \mathrm{C}$, $\mathrm{pH} 7.0$.

These results suggest that the microbial consortium is able to decolorize the dye completely only under microaerophilic condition. This is in agreement with previous report where aerobic conditions are known to inhibit decolorization of azo dyes primarily due to the competition in the oxidation of reduced electron carriers (e.g., NADH) with either oxygen or azo groups as the electron receptor [57]. The inhibition of Trypan Blue decolorization under aerobic conditions might be due to the the azo nature of the dye. It is stated that under aerobic conditions azo dyes are resistant to breakdown by bacteria [58]. Similarly, Phugare et al. during their study on the biodegradation of the textile azo dye Red HE3B in yeast extract medium using a developed microbial consortium-SDS observed that decolorization performance was tremendously inhibited under shaking conditions ( $20 \%$ in $24 \mathrm{~h}$ ) while complete dye removal was observed under microaerophilic conditions within only $1 \mathrm{~h}$ [59]. Hence, further degradation studies were carried out under microaerophilic conditions only. 


\subsection{Decolorization Parameters}

The efficiency of biodegradation processes is greatly influenced by the operational parameters. Thus, culture medium $\mathrm{pH}$, incubation temperature and dye concentration must be optimized for enhanced decolorization performance. The $\mathrm{pH}$ has a major effect on the rate of decolorization as the tolerance of bacteria to more acidic or alkaline $\mathrm{pH}$ values makes them suitable for biological treatment of dye wastewaters.

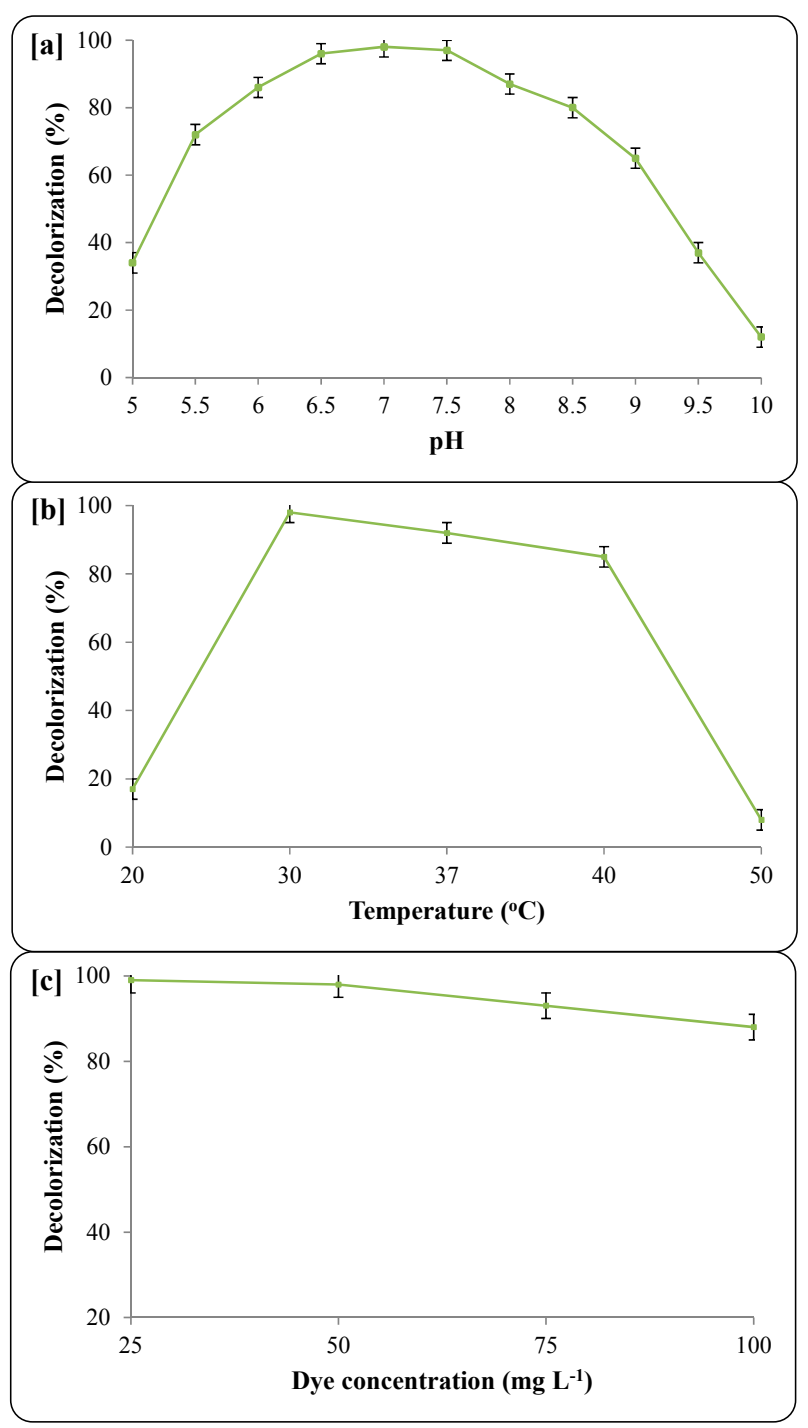

Figure 5. Effect of environmental parameters on decolorization of Trypan Blue (50 $\mathrm{mg} \cdot \mathrm{L}^{-1}$ ) by microbial consortium; (a) initial $\mathrm{pH}$ of pre-enriched culture medium, (b) incubation temperature, (c) various dye concentration. Decolorization was measured after $24 \mathrm{~h}$ of incubation. Data points represents the mean of three independent replicates, standard error of mean is indicated by error bars.

The maximum decolorization of Trypan Blue $\left(50 \mathrm{mg} \cdot \mathrm{L}^{-1}\right)$ was observed at $\mathrm{pH} 7.0$ and almost complete removal of dye was obtained within $24 \mathrm{~h}$ at $30 \pm 0.2{ }^{\circ} \mathrm{C}$ temperature (Figure 5a). The decolorization performance of the microbial consortium was not much affected when the $\mathrm{pH}$ was lowered to 6.0 or raised to 8.5 . However, at a more alkaline $\mathrm{pH}(10.0)$ the decolorization efficiency 
decreased and only $12 \%$ of the dye was removed within $24 \mathrm{~h}$. The $\mathrm{pH}$ of the medium has been known to be responsible for the transport of dye across cell membranes and thus considered a rate limiting factor [60]. The results of our study indicated that, though maximum dye decolorization was observed at $\mathrm{pH}$ 7.0, the enriched microbial consortium could be used over a wide range of $\mathrm{pH}$ values (6-8.5) for dye removal. Balapure et al. observed a similar decolorization pattern for the dye Reactive Blue 160 by mixed cultures consisting of eight bacterial strains, where maximum dye removal was found at pH 7.0 and it decreased slightly within the $\mathrm{pH}$ 6-8 range [48].

The degradation of the dye Trypan Blue was monitored as a function of incubation temperature. To optimize this parameter, microbial consortium-mediated decolorization was investigated at different incubation temperatures, while keeping the other conditions the same ( $\mathrm{pH} 7.0$, Trypan Blue $50 \mathrm{mg} \cdot \mathrm{L}^{-1}$, microaerophilic incubation). The microbial consortium appears to work well at $30 \pm 0.2{ }^{\circ} \mathrm{C}$ temperature; while lower and higher temperatures than the optimum slightly affected the decolorization rates. Almost $99 \%$ decolorization was observed at $30 \pm 0.2{ }^{\circ} \mathrm{C}$ within $24 \mathrm{~h}$; whereas an increase in temperature to 37 and $40 \pm 0.2{ }^{\circ} \mathrm{C}$ resulted into 92 and $85 \%$ performance within the same time, respectively (Figure 5b). However, a higher increase $\left(50 \pm 0.2{ }^{\circ} \mathrm{C}\right)$ or a decrease $\left(20 \pm 0.2{ }^{\circ} \mathrm{C}\right)$ in incubation temperature tremendously inhibited the decolorization ability of the microbial consortium to $8 \%$ and $17 \%$, respectively. The decrease in decolorization at 50 and $20 \pm 0.2{ }^{\circ} \mathrm{C}$ might be because of cessation of microbial growth and/or thermal denaturation of protein and enzymes. However, significant decolorization over a wide temperature range points to further use of this consortium for large scale remediation of dyes at ambient temperatures. Our results corroborate the results obtained by Phugare et al. who observed maximum textile effluent decolorization by the bacterial consortium SDS at $30{ }^{\circ} \mathrm{C}$ followed by a slight change at higher and lower temperatures [61]. The degradation potential of bacteria is known to be associated with their growth and the enzyme activities at the respective temperatures [61].

Dye concentration is known to have an inverse influence on microbial survival and decolorization efficiency. Most dyes are visible in water at concentrations as low as $1 \mathrm{mg} \cdot \mathrm{L}^{-1}$ and textile effluents have concentrations ranging from 10 to $200 \mathrm{mg} \cdot \mathrm{L}^{-1}$ [62], making it thus essential to evaluate the maximum dye decolorization capacity of a microbial consortium for further biodegradation purposes. As shown in Figure 5c, the complete decolorization (99\%) of Trypan Blue was observed for 25 and $50 \mathrm{mg} \cdot \mathrm{L}^{-1}$ dye concentrations within $24 \mathrm{~h}$. The increase in dye concentration beyond $50 \mathrm{mg} \cdot \mathrm{L}^{-1} \mathrm{slightly}$ affected decolorization performance as $93 \%$ and $88 \%$ removal was observed at 75 and $100 \mathrm{mg} \cdot \mathrm{L}^{-1}$ respectively. This decreased efficiency may be due to the toxicity of the dye and dye degradation metabolites formed at higher concentration [63]. Additionally, higher dye concentrations may also affect bacterial growth [64]. However, the ability of the microbial consortium to completely decolorize the highly sturdy and recalcitrant dye Trypan Blue $\left(50 \mathrm{mg} \cdot \mathrm{L}^{-1}\right)$ in agricultural waste medium demonstrated the importance of the present study. In summary, a microbial consortium grown in WB medium was found to be very effective for decolorization of Trypan Blue under optimum $\mathrm{pH}$, temperature and dye concentrations, and thus could be used for large scale treatment of benzidine-based dyes. 


\subsection{Mineralization of Dye}

The primary objective of biodegradation processes is to mineralize the dye into $\mathrm{CO}_{2}$ and $\mathrm{H}_{2} \mathrm{O}$ without generation of toxic intermediates. However, biodegradation of several azo dyes results into the formation of toxic metabolites such as aromatic amines which are known to be mutagenic and/or carcinogenic [27,65]. Thus, it is necessary to evaluate the degradation products for the presence of aromatic amines before being released into environmental sinks. Analysis of the decolorization process at regular time intervals suggests that $0.10 \mathrm{mM}$ and $0.24 \mathrm{mM}$ of aromatic amines were formed within the first 8 and $16 \mathrm{~h}$, respectively (Table 1), but it was interesting to note that no amines were detected after the complete $24 \mathrm{~h}$ decolorization process. The presence of amines up to $16 \mathrm{~h}$ of incubation may be due to the initial reductive cleavage of azo bond by azoreductases under microaerophilic conditions. Azoreductases are known to utilize azo dyes as terminal electron acceptors in oxygen limiting conditions [66]. Further disappearance of the formed amines might be due to oxidative breakdown by laccase in presence of the remaining molecular oxygen. The role of laccase in oxidative cleavage of azo dyes is well documented [67]. This is very similar to what we have reported for decolorization of the azo dye Rubine GFL by a fungal-bacterial consortium, and thus underscores the usefulness of this consortium to decolorize benzidine-based azo dyes without generating aromatic amines.

Table 1. Decolorization of Trypan Blue $\left(50 \mathrm{mg} \cdot \mathrm{L}^{-1}\right)$ by a bacterial consortium and formation of aromatic amines at regular time of intervals.

\begin{tabular}{ccc}
\hline Incubation Time (h) & Decolorization (\%) & Amine Conc. (mM) \\
\hline 0 & $0 \pm 0.0$ & n.d. \\
8 & $34 \pm 1.5$ & $0.10 \pm 0.01$ \\
16 & $70 \pm 2.0$ & $0.24 \pm 0.02$ \\
24 & $98 \pm 1.0$ & n.d. \\
\hline
\end{tabular}

n.d. $=$ Not detected. Values are mean of three experiments, \pm Standard deviation for all the data.

Degradation of the dye Trypan Blue by a microbial consortium using optimized parameters was accompanied by mineralization analysis. The mineralization of a dye as represented by the important environmental parameters TOC and COD removal ratio were measured for the untreated dye and decolorized medium. Results of these parameters after complete decolorization $(24 \mathrm{~h})$ of dye by the microbial consortium revealed a decrease in the values of TOC and COD by $64 \%$ and $88 \%$, respectively (Table 2). The COD removal by the microbial consortium was significant compared to solar energy-assisted photo-Fenton oxidation of Trypan Blue [14], which achieved a COD removal of $51.6 \%$. The complete decolorization with high TOC and COD removal efficiency indicates the potential of the microbial consortium for decolorization as well as mineralization of Trypan Blue dye in WB medium. Thus, from an environmental as well as an economical point of view, the present microbial consortium could be used for decolorization of benzidine-based dyes at large scale since it reduced TOC and COD significantly while growing on agricultural waste WB under submerged conditions. To the best of our knowledge, there has been no use of wheat bran as a growth medium for biodegradation of benzidine-based dyes under submerged conditions. 
Table 2. Environmental parameters of the untreated dye Trypan Blue $\left(50 \mathrm{mg} \cdot \mathrm{L}^{-1}\right)$ and after treatment with microbial consortium.

\begin{tabular}{ccc}
\hline Environmental Parameters & Untreated Dye & After Decolorization (24 h) \\
\hline TOC $\left(\mathrm{mg} \cdot \mathrm{L}^{-1}\right)$ & $1642 \pm 3.0$ & $591 \pm 4.0$ \\
$\mathrm{COD}\left(\mathrm{mg} \cdot \mathrm{L}^{-1}\right)$ & $1265 \pm 5.0$ & $152 \pm 3.0$ \\
Color $(\%)$ & $100 \pm 0.0$ & $1 \pm 1.0$ \\
\hline
\end{tabular}

Values are mean of three experiments \pm standard deviation (SD).

Since the cost of the medium plays a very important role in commercial applications of bioremediation methods, the real market price analysis of wheat bran with the most commonly used defined growth medium nutrient broth was carried out. The price of wheat bran on the world's biggest online trading company Alibaba.com is US \$154-162/metric ton; while that of nutrient broth is US \$5000-20000/metric ton. Such a huge price difference between wheat bran and nutrient broth underlines the cost effectiveness of the present work to use it for large scale treatment of dye wastewaters. In addition, the remaining agricultural waste substrate after media preparation could be used as a low cost adsorbent for dyes and subsequent biodegradation in SSF-based processes [31].

\subsection{Enzyme Studies}

Decolorization of dyes usually occurs by enzymatic means. A recent book chapter by Telke et al. has shown that oxidative enzymes such as laccases, tyrosinase, veratryl alcohol oxidase from various microorganisms can oxidize dyes; while a few important reductive enzymes such as azoreductase, and NADH-DCIP reductase can perform a reductive breakdown of azo dyes [68]. In the present study, analysis of the enzymes responsible for biotransformation of the dye, viz. laccase, lignin peroxidase, azoreductase, and NADH-DCIP reductase revealed that microbial consortium produce these enzymes and thus the dye decolorization observed was likely to be enzymatically caused. Analysis of the oxidative enzyme laccase, tryrosinase and veratryl alcohol oxidase showed induction of $275 \%, 21 \%$ and $62 \%$, respectively, after decolorization when compared with control cultures (Table 3). Similarly, the reductive enzymes azoreductase (500\%) and NADH-DCIP reductase (264\%) from decolorized medium also showed induction but at very high levels. Significantly higher activity of azoreductase and NADH-DCIP reductase in decolorized culture medium suggest a reductive cleavage of azo bonds. It is well known that azoreductase performs the initial reductive cleavage of azo bonds in microaerophilic conditions [69]. On the other hand, laccase was also found highly induced indicating the further oxidation of formed metabolites. The role of laccase in the oxidation of azo dyes and/or their degradation metabolites has been previously reported [67,70]. These obtained results showed high oxidative as well as reductive enzyme activities in decolorized dye culture medium as compared to control cultures. It suggests that enzyme activities were induced only if the microbial consortium was exposed to dye; indicating the combined action of all these enzymes is responsible for the decolorization and degradation of the dye Trypan Blue. Our results are consistent with the findings of Balapure et al., in which induction in the activities of laccase, tyrosinase, azoreductase and NADH-DCIP reductase were observed in azo dye decolorized medium [71]. The formation of aromatic amines within the first few hours of the decolorization process and further disappearance 
after complete decolorization of dye thus indicates the initial reductive cleavage of dye by azoreductase and further oxidation of the formed amines by laccase.

Table 3. Enzyme activities in control cells and cells obtained after decolorization of dye Trypan Blue $\left(50 \mathrm{mg} \cdot \mathrm{L}^{-1}\right)$ by microbial consortium.

\begin{tabular}{ccc}
\hline Enzymes & Control $(\mathbf{0 ~ h})$ & Test (After Decolorization for 24 h) \\
\hline Laccase $^{1}$ & $0.4 \pm 0.01$ & $1.5 \pm 0.03 * * *$ \\
Tyrosinase $^{2}$ & $0.8 \pm 0.02$ & $0.97 \pm 0.03 * *$ \\
Veratryl alcohol oxidase $^{3}$ & $0.80 \pm 0.02$ & $1.3 \pm 0.05 * * *$ \\
Azoreductase $^{4}$ & $0.6 \pm 0.01$ & $3.6 \pm 0.04 * * *$ \\
NADH-DCIP reductase $^{5}$ & $12.2 \pm 1.1$ & $44.4 \pm 4.2 * * *$ \\
\hline
\end{tabular}

Control $=$ Enzyme extracted after enrichment of microbial consortium. Test $=$ Enzymes extracted from the dye decolorized culture medium. Values are mean of three experiments \pm standard error mean (SEM), significantly different from control cells at $* p<0.05, * * p<0.01$ and $* * * p<0.001$ by one-way analysis of variance (ANOVA) with Tukey Kramer comparison test. ${ }^{1} \mu \mathrm{M}$ of ABTS oxidized $\mathrm{min}^{-1} \mathrm{~mL}$ of enzyme ${ }^{-1} \mathrm{mg}$ of protein ${ }^{-1} ;{ }^{2} \mu \mathrm{M}$ of catechol oxidized $\min ^{-1} \mathrm{~mL}$ of enzyme ${ }^{-1} \mathrm{mg}$ of protein ${ }^{-1} ;{ }^{3} \mu \mathrm{M}$ of veratryl alcohol oxidized $\mathrm{min}^{-1} \mathrm{~mL}$ of enzyme $\mathrm{m}^{-1} \mathrm{mg}$ of protein ${ }^{-1} ;{ }^{4} \mu \mathrm{M}$ of Methyl red reduced $\mathrm{min}^{-1} \mathrm{~mL}$ of enzyme $\mathrm{m}^{-1} \mathrm{mg}$ of protein ${ }^{-1} ;{ }^{5} \mu \mathrm{M}$ of DCIP reduced $\mathrm{min}^{-1} \mathrm{~mL}$ of enzyme ${ }^{-1} \mathrm{mg}$ of protein ${ }^{-1}$.

\subsection{Biodegradation Studies}

In addition to mineralization studies, the biodegradation of Trypan Blue dye was monitored by HPLC, FTIR and GC-MS analysis as well. Figure 6 shows the HPLC chromatograms of control dye Trypan Blue and its degradation products after treatment with the microbial consortium. The HPLC profile of the control dye showed a single peak at a retention time of $2.318 \mathrm{~min}$ (Figure 6a). The microbial consortium-treated dye sample showed six peaks at different retention times which could correspond to the degradation metabolites. A total of two major peaks at retention time of 4.903 and 13.637 min as well as four minor peaks at 3.433, 6.176, 7.173 and 11.719 were observed (Figure 6b). As can be seen in the treated sample chromatogram, the appearance of six new peaks at various retention times indicates the total conversion of Trypan Blue dye into different metabolites. HPLC has been previously reported for the analysis of dye degradation metabolites [27,31,61]. Furthermore, in order to identify these metabolites by formed microbial consortium and to come up with a possible degradation pathway of Trypan Blue, we employed FTIR and GC-MS analyses.

As shown in Figure 7, the FTIR spectra of control dye Trypan Blue showed vibrations at $2976.08 \mathrm{~cm}^{-1}$ (epoxides OC-H stretching), $2884.66 \mathrm{~cm}^{-1}$ (alkanes $\mathrm{C}-\mathrm{H}$ stretching), $2359.74 \mathrm{~cm}^{-1}$ (amines $\mathrm{NH}^{+}$stretching), 1612.30-1581.34 $\mathrm{cm}^{-1}$ (double azo bond $-\mathrm{N}=\mathrm{N}$ stretching), $1492.96 \mathrm{~cm}^{-1}$ (nitrosamines $\mathrm{N}=\mathrm{O}$ stretching), $1340.62 \mathrm{~cm}^{-1}$ (azides $-\mathrm{N}_{3}$ stretching), $1209.38 \mathrm{~cm}^{-1}$ (aliphatic amines $\mathrm{C}-\mathrm{N}$ vibration), $819.94 \mathrm{~cm}^{-1}$ (benzene ring with three adjacent $\mathrm{H}$ atom $\mathrm{C}-\mathrm{H}$ deformation) and the right part spectral region from 673.96 to $643.32 \mathrm{~cm}^{-1}$ (carbonated impurities). 


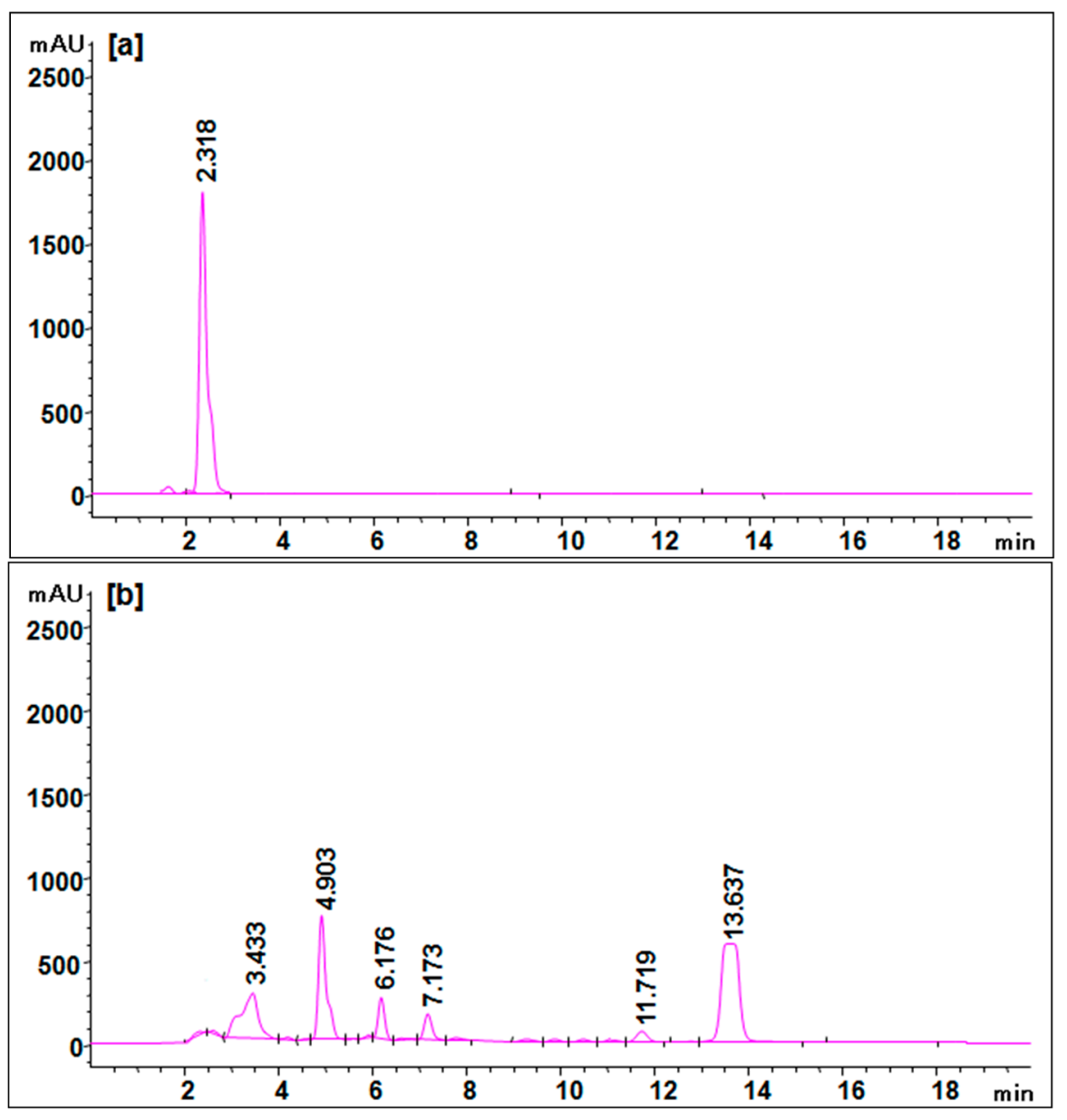

Figure 6. HPLC elution profile of (a) control dye Trypan Blue and (b) its degradation product at $210 \mathrm{~nm}$.

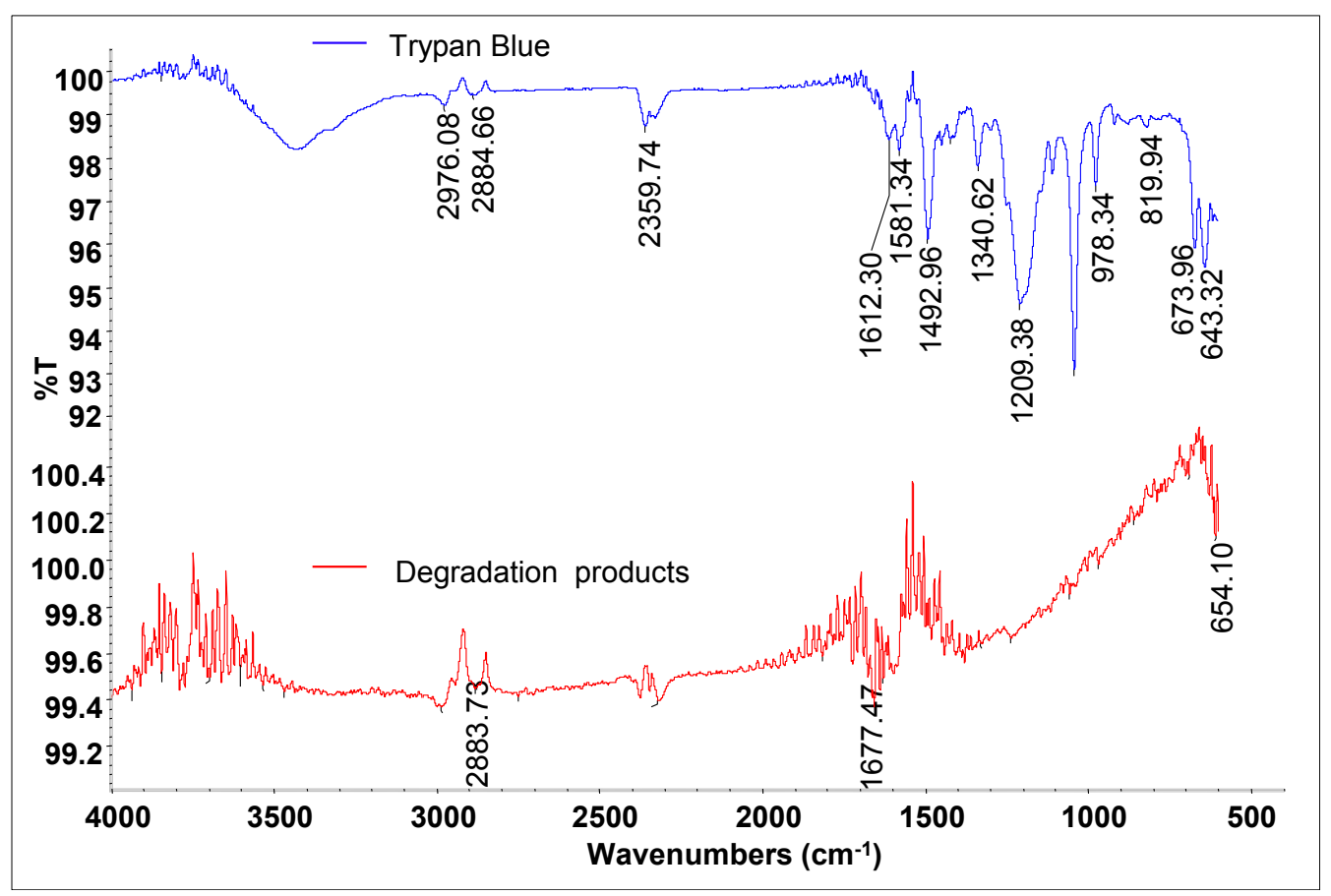

Figure 7. FTIR analysis of a Trypan Blue control and its degradation products obtained after $24 \mathrm{~h}$ treatment with the microbial consortium. 
After $24 \mathrm{~h}$ of treatment with microbial consortium, a different pattern of absorption peaks was observed for dye extracted products. The FTIR profile of dye decolorized products showed peaks at $2883.73 \mathrm{~cm}^{-1}$ (alkanes $\mathrm{C}-\mathrm{H}$ stretching) and $1677.47 \mathrm{~cm}^{-1}$ (nitrites $\mathrm{N}=\mathrm{O}$ stretching). Two peaks of untreated dye Trypan Blue at 1612.30 and $1581.34 \mathrm{~cm}^{-1}$ associated with the azo bonds were totally disappeared in decolorized products indicates the reductive cleavage of dye molecule. At the same time, number of peaks ranging from 810 to $750 \mathrm{~cm}^{-1}$ corresponding to benzene ring structure of Trypan Blue were also disappeared indicating the opening of dye benzene ring. These results evidently suggested reductive cleavage of azo bond of dye Trypan Blue by azoreductase and further degradation of formed metabolites by oxidative enzymes.

The intermediate metabolites formed were identified by GC-MS analysis and shown in Table 4. The GC-MS data supported the cleavage of azo bond leading to the formation of disodium 3,5-diamino-4-hydroxynaphthalene-2,7-disulfonate with a mass peak of 378. Another metabolite identified was naphthalen-1-ol, with a mass peak of 144. A possible pathway for the degradation of Trypan Blue was put forth on the basis of these identified products. As observed in the FTIR analysis of the control dye, peaks corresponding to high molecular weight compounds were not detected by GC-MS of the decolorized dye products, suggesting a complete breakdown of Trypan Blue into low molecular weight compounds.

Table 4. GC-Mass spectra of products obtained after degradation of Trypan Blue by microbial consortium.

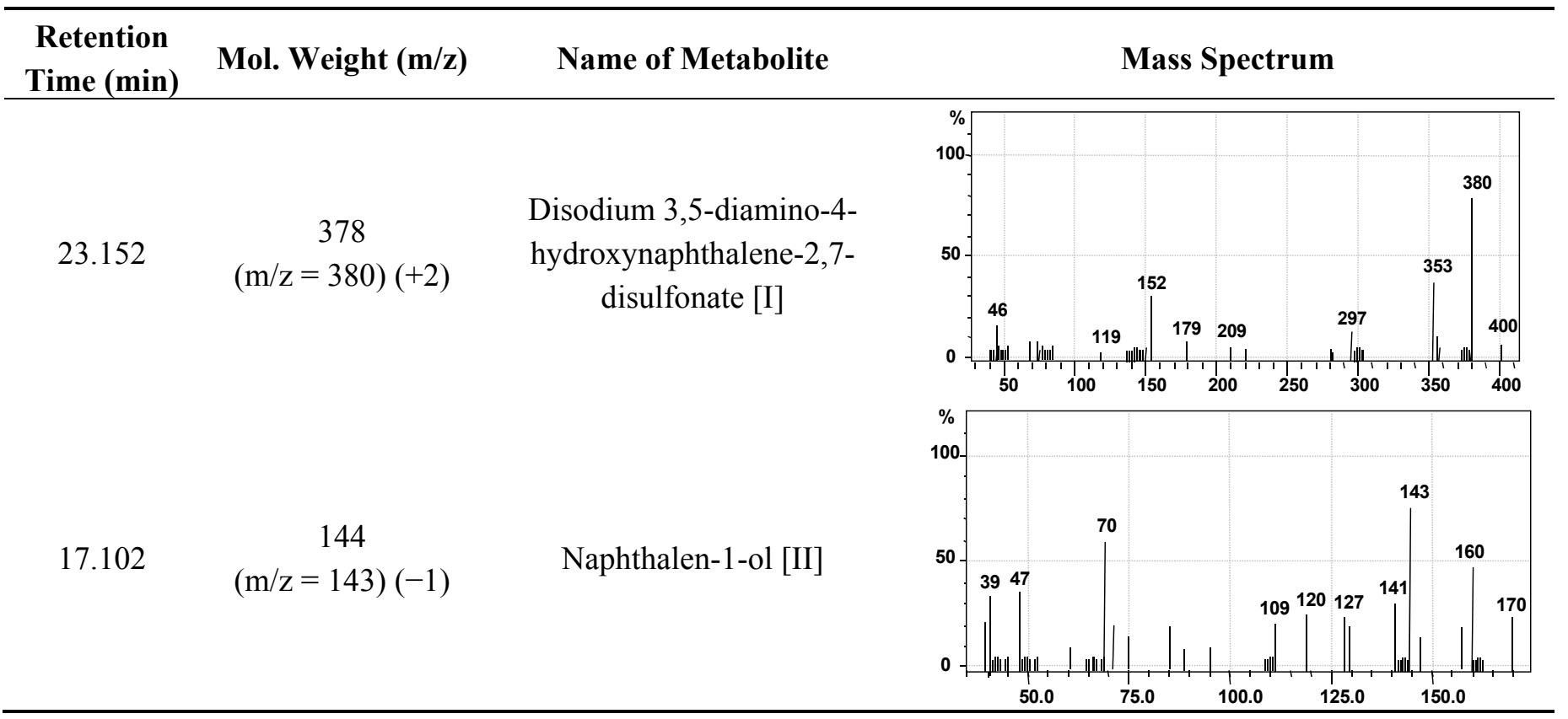

A possible mechanistic pathway for degradation of Trypan Blue by microbial consortium has been proposed and shown in Figure 8. As seen in figure, the initial step in bacterial degradation of azo dyes under microaerophilic condition involves the reductive cleavage of $-\mathrm{N}=\mathrm{N}-$ bond facilitated by reductases leading to formation of low molecular weight colorless aromatic amines [72,73]. The above FTIR and GC-MS analysis data of the dye degradation products clearly confirms the initial reductive cleavage of Trypan Blue resulting into formation of an intermediate metabolite disodium 3,5-diamino-4-hydroxynaphthalene-2,7-disulfonate (A). This reductive cleavage is also supposed to 
generated the metabolite (I); however, further mineralization via the TCA cycle was anticipated due to the presence of tyrosinase activity (Table 3 ) and thus this was not detected by the GC-MS analysis. With the continuation of decolorization process, the metabolite-A was converted into a lower molecular weight compound naphthalen-1-ol (B) as final product via the oxidation by oxidative enzymes like laccase, tyrosinase or veratryl alcohol oxidase. The significant induction in the activity of laccase demonstrated their active role in oxidation of metabolite A.

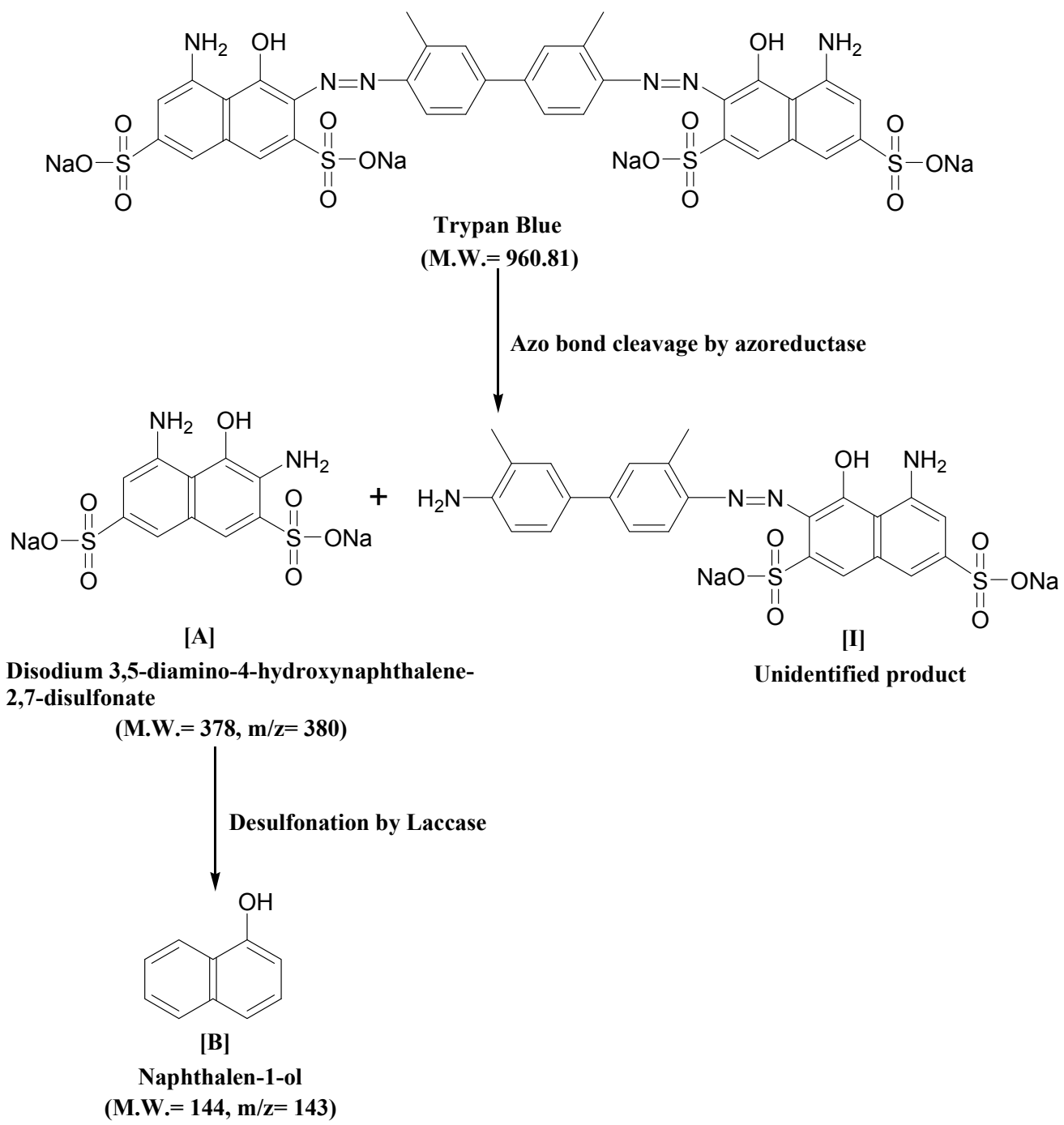

Figure 8. Possible degradation mechanism of Trypan Blue by the microbial consortium based on the GC-MS data and enzyme activities.

\subsection{Toxicity Studies}

Analysis of the ecological and genetic impact of dyes on the growth of crop plants is of great importance as those are commonly consumed by humans. Results of phytotoxicity tests with $S$. vulgare and $P$. mungo showed that seeds exposed to untreated dye showed inhibition of germination by $80 \%$ and $70 \%$, respectively, and also less shoot elongation $(3.5$ and $4.9 \mathrm{~cm})$ and root $(1.9$ and $1.8 \mathrm{~cm})$ lengths were observed (Table 5). On the other hand, seeds irrigated with dye degradation products showed $90 \%$ germination with good elongation of shoot $(9.5$ and $10.1 \mathrm{~cm})$ and root $(3.8$ and $4.6 \mathrm{~cm})$ lengths for both the $S$. vulgare and $P$. mungo plants, respectively. These parameters are almost similar 
to those of seeds irrigated with distilled water, where $100 \%$ germination, 9.8 and $10.2 \mathrm{~cm}$ shoot length and 4.1 and $4.8 \mathrm{~cm}$ root lengths were observed. These results are consistent with the findings of Kadam et al. [31], in which over $90 \%$ germination of both the plant seeds and considerable elongation of shoot and root lengths were observed for the products of degradation of the dye Solvent Red 5B by Providensia staurti strain EbtSPG. Similarly, inhibition of germination, retarded shoot and root lengths in the presence of the dye Green HE4BD and their subsequent increase in dye degradation products by a developed bacterial consortium were reported [74]. Thus, phytotoxicity analysis indicated that the microbial consortium converted the toxic dye Trypan Blue into non-toxic metabolites.

Table 5. Phytotoxicity of Trypan Blue $\left(50 \mathrm{mg} \mathrm{L}^{-1}\right)$ and its degradation products extracted after degradation $(24 \mathrm{~h}$ ) by microbial consortium.

\begin{tabular}{ccccccc}
\hline \multirow{2}{*}{ Samples } & \multicolumn{3}{c}{$\boldsymbol{S .}$ vulgare } & \multicolumn{3}{c}{$\boldsymbol{P . ~ m u n g o}$} \\
\cline { 2 - 7 } & $\begin{array}{c}\text { Germination } \\
\mathbf{( \% )}\end{array}$ & $\begin{array}{c}\text { Shoot Length } \\
\mathbf{( c m )}\end{array}$ & $\begin{array}{c}\text { Root Length } \\
(\mathbf{c m})\end{array}$ & $\begin{array}{c}\text { Germination } \\
\mathbf{( \% )}\end{array}$ & $\begin{array}{c}\text { Shoot Length } \\
\text { (cm) }\end{array}$ & $\begin{array}{c}\text { Root Length } \\
(\mathbf{c m})\end{array}$ \\
\hline $\begin{array}{c}\text { Distilled water } \\
\text { Trypan Blue }\end{array}$ & 100 & $9.8 \pm 0.2$ & $4.1 \pm 0.2$ & 100 & $10.2 \pm 0.3$ & $4.8 \pm 0.3$ \\
$\begin{array}{c}\text { Degradation } \\
\text { products }\end{array}$ & 20 & $3.5 \pm 0.2 *$ & $1.9 \pm 0.1 *$ & 30 & $4.9 \pm 0.2 *$ & $1.8 \pm 0.2 *$ \\
\hline
\end{tabular}

Values are mean of three experiments, \pm SEM, significantly different from control (seed germinated in distilled water) at $* p<0.1$ by the one-way ANOVA with Tukey-Kramer multiple comparison test.

Acute toxicity tests with $D$. magna have been suggested as a first screening method for the assessment of any lethal toxicity of chemicals to mammals and humans [75]. The use of D. magna as a toxicity indicator for evaluation of textile effluent quality and also in the assessment of treatment plant efficiency was also documented [76]. In this study, an acute toxicity test with original $\left(50 \mathrm{mg} \cdot \mathrm{L}^{-1}\right)$, $25 \%$ and 50\% Trypan Blue-containing medium showed complete mortality of D. magna, whereas 50\% mortality was observed in $75 \%$ dye diluted culture medium (Table 6). Treatment of dye with the microbial consortium revealed the complete detoxification of dye degradation products as no D. magna mortality was found. These finding suggest that any release of untreated Trypan Blue dye poses a risk to the environment and to human health, whereas dye treatment with the microbial consortium could be used for complete detoxification.

Table 6. Mortality of $D$. magna exposed to $75 \%$ dilution of the culture supernatants containing Trypan Blue treated with microbial consortium.

\begin{tabular}{cc}
\hline Samples & Mortality (\%) \\
\hline Distilled water & $0 \pm 0.0$ \\
Trypan Blue & $60 \pm 3.0$ \\
Decolorized medium & $0 \pm 0.0$ \\
\hline
\end{tabular}

Values are mean of three experiments, \pm SEM.

\section{Conclusions}

Agricultural waste wheat bran was utilized as a growth medium for the biodegradation of the benzidine-based carcinogenic dye Trypan Blue under submerged conditions. The ability of the 
microbial consortium to degrade the dye was mainly due to the activities of oxidative and reductive enzymes. The proposed pathway suggests biodegradation of Tryphan Blue. FTIR and HPLC analysis confirmed the degradation of the dye by the microbial consortium. Commonly used models in environmental risk assessment of dyes like phytotoxicity and acute toxicity tests confirmed the biotransformation of the dye into non-toxic forms. Clearly, these findings suggest that WB medium is a promising low cost alternative to defined growth medium for the bioremediation and detoxification of hazardous dyes.

\section{Acknowledgments}

The authors would like to thank both the anonymous referees for their constructive comments and suggestions.

\section{Author Contributions}

Harshad Lade wrote and revise the paper. Avinash Kadam contributed in performing the actual experiments, construction of biodegradation pathway and statistical analysis. Diby Paul and Sanjay Govindwar supervised the work.

\section{Conflict of Interests}

The authors declare no conflict of interest.

\section{References}

1. US EPA. Dyes Derived from Benzidine and Its Congeners. U.S. Environmental Protection Agency. 2010. Available online: http://www.epa.gov/oppt/existingchemicals/pubs/actionplans/benzidine. html (accessed on 2 March 2015).

2. CEPA (Canadian Environmental Protection Act., 1999): Notice with Respect to Certain Aromatic Amines and Aromatic Azo- and Benzidine-Based Substances. Canada Gazette, Part I, Volume 145, No. 51, Supplement to the Canada Gazette. Available online: www.gazette.gc.ca/rp-pr/ p1/2011/index-eng.html (accessed on 2 March 2015).

3. Morton, K.C.; King, K.M.; Baetcke, K.P. Metabolism of benzidine and subsequent nucleic acid binding and mutagenicity. Cancer Res. 1979, 39, 3107-3113.

4. Morgan, D.L.; Dunnick, J.K.; Goehl, T.; Jokinen, M.P.; Matthews, H.B.; Zeiger, E.; Mennear, J.H. Summary of the National Toxicology Program benzidine dye initiative. Environ. Health Perspect. 1994, 102, 63-78.

5. Combes, R.D.; Haveland-Smith, R.B. A review of the genotoxicity of food, drug and cosmetic colours and other azo triphenylmethane and xanthene dyes. Mutat. Res. 1982, 98, 101-248.

6. Chung, K.T.; Cerniglia, C.E. Mutagenicity of azo dyes: Structure-activity relationships. Mutat. Res. 1992, 277, 201-220.

7. Turesky, R.J. Interspecies metabolism of heterocyclic aromatic amines and the uncertainties in extrapolation of animal toxicity data for human risk assessment. Mol. Nutr. Food Res. 2005, 49, 101-117. 
8. Dumont, J.; Josse, R.; Lambert, C.; Antherieu, S.; Le Hegarat, L.; Aninat, C.; Robin, M.A.; Guguen-Guillouzo, C.; Guillouzo, A. Differential toxicity of hetero- cyclic aromatic amines and their mixture in metabolically competent HepaRG cells. Toxicol. Appl. Pharmacol. 2010, 245, 256-263.

9. Jager, I.; Hafner, C.; Schneider, K. Mutagenicity of different textile dye products in Salmonella typhimurium and mouse lymphoma cells. Mutat. Res. 2004, 561, 35-44.

10. Brown, J.P.; Dietrich, P.S. Mutagenicity of selected sulfonated azo dyes in the Salmonella/microsome assay: Use of aerobic and anaerobic activation procedures. Mutat. Res. 1983, 116, 305-315.

11. Gillman, T.; Kinns, A.M.; Hallowes, R.C.; Lloyd, J.B. Malignant lymphoreticular tumors induced by trypan blue and transplanted in inbred rats. J. Natl. Cancer Inst. 1973, 50, 1179-1193.

12. Saratale, R.G.; Saratale, G.D.; Chang, J.S.; Govindwar, S.P. Bacterial decolorization and degradation of azo dyes: A review. J. Taiwan Inst. Chem. Eng. 2011, 42, 138-157.

13. Kadam, A.A.; Lade, H.S.; Patil, S.M.; Govindwar, S.P. Low cost $\mathrm{CaCl}_{2}$ pretreatment of sugarcane bagasse for enhancement of textile dyes adsorption and subsequent biodegradation of adsorbed dyes under solid state fermentation. Bioresour. Technol. 2013, 132, 276-284.

14. Dutta, A.; Banerjee, P.; Sarkar, D.; Bhattacharjee, S.; Chakrabarti, S. Degradation of Trypan Blue in wastewater by sunlight-assisted modified photo-Fenton reaction. Desalin. Water Treat. 2014, 8 , $1-9$.

15. Saratale, R.G.; Saratale, G.D.; Chang, J.S.; Govindwar, S.P. Decolorization and biodegradation of textile dye Navy blue HER by Trichosporon beigelii NCIM-3326. J. Hazard. Mater. 2009, 166, 1421-1428.

16. Lucas, M.S.; Peres, J.A. Decolorization of the azo dyeReactive Black 5 by Fenton and photo-Fenton oxidation. Dyes Pigm. 2006, 71, 236-244.

17. Robinson, T.; Nigam, P. Remediation of textile dye waste water using a white rot fungus Bjerkandera adusta through solid-state fermentation (SSF). Appl. Biochem. Biotechnol. 2008, $151,618-628$.

18. Muruganandham, M.; Swaminathan, M. Solar driven decolourisation of Reactive Yellow 14 by advanced oxidation processes in heterogeneous and homoge-neous media. Dyes Pigm. 2007, 72, 137-143.

19. Muller, J.P.; Jekel, M. Comparison of advanced oxida-tion processes if flow-through pilot plants (Part I). Water Sci. Technol. 2001, 44, 303-309.

20. Rosenfeldt, E.J.; Linden, K.G.; Canonica, S.; Von, G.U. Comparison of the efficiency of *OH radical formation during ozonation and the advanced oxidation processes $\mathrm{O}_{3} / \mathrm{H}_{2} \mathrm{O}_{2}$ and $\mathrm{UV} / \mathrm{H}_{2} \mathrm{O}_{2}$. Water Res. 2006, 40, 3695-3704.

21. Butani, N.; Jobanputra, J.; Bhatiya, P.; Patel, R. Recent biological technologies for textile effluent treatment. Int. Res. J. Biol. Sci. 2013, 2, 77-82.

22. Kalyani, D.C.; Telke, A.A.; Dhanve, R.S.; Jadhav, J.P. Ecofriendly biodegradation and detoxification of Reactive Red 2 textile dye by newly isolated Pseudomonas sp. SUK1. J. Hazard. Mater. 2009, 163, 735-742.

23. Parshetti, G.K.; Kalme, S.D.; Gomare, S.S.; Govindwar, S.P. Biodegradation of reactive blue-25 by Aspergillus. ochraceus NCIM-1146. Bioresour. Technol. 2007, 98, 3638-3642. 
24. Khataee, A.R.; Zarei, M.; Pourhassan, M. Application of microalga Chlamydomonas sp. for biosorptive removal of a textile dye from contaminated water: Modelling by a neural network. Environ. Technol. 2009, 30, 1615-1623.

25. Kulkarni, A.N.; Kadam, A.A.; Kachole, M.S.; Govindwar, S.P. Lichen Permelia perlata: A novel system for biodegradation and detoxification of disperse dye Solvent Red 24. J. Hazard. Mater. 2014, 276, 461-468.

26. Khandare, R.V.; Kabra, A.N.; Kurade, M.B.; Govindwar, S.P. Phytoremediation potential of Portulaca grandiflora Hook. (Moss-Rose) in degrading a sulfonated diazo reactive dye Navy Blue HE2R (Reactive Blue 172). Bioresour. Technol. 2011, 102, 6774-6777.

27. Lade, H.S.; Waghmode, T.R.; Kadam, A.A.; Govindwar, S.P. Enhanced biodegradation and detoxification of disperse azo dye Rubine GFL and textile industry effluent by defined fungal-bacterial consortium. Int. Biodeterior. Biodegrad. 2012, 72, 94-107.

28. Kabra, A.N.; Khandare, R.V.; Govindwar, S.P. Development of a bioreactor for remediation of textile effluent and dye mixture: A plant-bacterial synergistic strategy. Water Res. 2013, 47, 1035-1048.

29. Singh, R.; Kapoor, V.; Kumar, V. Utilization of agro-industrial wastes for the simultaneous production of amylase and xylanase by thermophilic Actinomycetes. Braz. J. Microbiol. 2012, 43, $1545-1552$.

30. Kadam, A.A.; Telke, A.A.; Jagtap, S.S.; Govindwar, S.P. Decolorization of adsorbed textile dyes by developed consortium of Pseudomonas sp. SUK1 and Aspergillus. ochraceus NCIM-1146 under solid state fermentation. J. Hazard. Mater. 2011, 189, 486-494.

31. Kadam, A.A.; Kamatkar, J.D.; Khandare, R.V.; Jadhav, J.P.; Govindwar, S.P. Solid-state fermentation: Tool for bioremediation of adsorbed textile dyestuff on distillery industry waste-yeast biomass using isolated Bacillus cereus strain EBT1. Environ. Sci. Poll. Res. 2013, 20, 1009-1020.

32. Waghmare, P.R.; Kadam, A.A.; Saratale, G.D.; Govindwar, S.P. Enzymatic hydrolysis and characterization of waste lignocellulosic biomass produced after dye bioremediation under solid state fermentation. Bioresour. Technol. 2014, 168, 136-141.

33. Krishna, C. Solid-state fermentation systems-an overview. Crit. Rev. Biotechnol. 2005, 25, 1-30.

34. Gomathi, D.; Muthulakshmi, C.; Kumar, D.G.; Ravikumar, G.; Kalaiselvi, M.; Uma, C. Submerged fermentation of wheat bran by Aspergillus. flavus for production and characterization of carboxy methyl cellulose. Asian Pac. J. Trop Biomed. 2012, 2, S67-S73.

35. Liang, Y.L.; Zhang, Z.; Wu, M.; Wu, Y.; Feng, J.-X. Isolation, screening, and identification of cellulolytic bacteria from natural reserves in the subtropical region of China and optimization of cellulase production by Paenibacillus. terrae ME27-1. BioMed. Res. Int. 2014, 2014, doi:10.1155/2014/512497.

36. El-Shishtawy, R.M.; Mohamed, S.A.; Asiri, A.M.; Gomaa, A.B.; Ibrahim, I.H.; Al-Talhi, H.A. Solid fermentation of wheat bran for hydrolytic enzymes production and saccharification content by a local isolate Bacillus megatherium. BMC Biotechnol. 2014, 14, 1-19.

37. Dubois, M.; Gilles, K.A.; Hamilton, J.K.; Rebers, P.A.; Smith, F. Colorimetric method for determination of sugars and related substances. Anal. Chem. 1956, 28, 350-356. 
38. Lowry, O.H.; Rosebrough, N.J.; Farr, A.L.; Randall, R.J. Protein measurement with the Folin phenol reagent. J. Biol. Chem. 1951, 193, 265-275.

39. Ausubel, F.M.; Brent, R.; Kingston, R.E.; Moore, D.D.; Seidman, J.G.; Smith, J.A.; Struhl, K. Preparation and analysis of DNA. In Current Protocols in Molecular Biology; John Wiley and Sons: New York, NY, USA, 1997; p. 66.

40. Joshi, S.M.; Inamdar, S.A.; Patil, S.M.; Govindwar, S.P. Molecular assessment of shift in bacterial community in response to Congo Red. Int. Biodeterior. Biodegrad. 2013, 77, 18-21.

41. Marik, J.; Song, A.; Lam, K.S. Detection of primary aromatic amines on solid phase. Tetrahedron Lett. 2003, 44, 4319-4320.

42. APHA. Standard Methods for the Examination of Water and Wastewater, 20th ed.; American Public Health Association: Washington, DC, USA, 1998.

43. Wolfenden, B.S.; Willson, R.L. Radical-cations as reference chromogens in kinetic studies of ono-electron transfer reactions: pulse radiolysis studies of 2,2'-azinobis-(3-ethylbenzthiazoline-6sulphonate). J. Chem. Soc. Perkin Trans. 1982, 2, 805-812.

44. Zhang, X.; Flurkey, W.H. Phenoloxidases in Portabella mushrooms. J. Food Sci. 1997, 62, 97-100.

45. Jadhav, U.U.; Dawkar, V.V.; Tamboli, D.P.; Govindwar, S.P. Purification and characterization of veratryl alcohol oxidase from Comamonas sp. UVS and its role in decolorization of textile dyes. Biotechnol. Bioprocess. Eng. 2009, 14, 369-376.

46. Chen, H.; Hopper, S.L.; Cerniglia, C.E. Biochemical and molecular characterization of an azoreductase from Staphylococcus aereus, a tetrameric NADPH-dependent flavoprotein. Microbiology 2005, 151, 1433-1441.

47. Salokhe, M.D.; Govindwar, S.P. Effect of carbon source on the biotransformation enzyme in Serratia. marcescens. World J. Microbiol. Biotechnol. 1999, 15, 259-263.

48. Balapure, K.H.; Jain, K.; Chattaraj, S.; Bhatt, N.S. Madamwar, D. Co-metabolic degradation of diazo dye- reactive blue 160 by enriched mixed cultures BDN. J. Hazard. Mater. 2014, 279, $85-95$.

49. Agrawal, S.; Tipreb, D.; Patelc, B.; Daveb, S. Optimization of triazo Acid Black 210 dye degradation by Providencia sp. SRS82 and elucidation of degradation pathway. Process. Biochem. 2014, 49, 110-119.

50. Jain, K.; Shah, V.; Chapla, D.; Madamwar, D. Decolorization and degradation of azo dyeReactive Violet 5R by an acclimatized indigenous bacterial mixed cultures-SB4 isolated from anthropogenic dye contaminated soil. J. Hazard. Mater. 2012, 213-214, 378-386.

51. Franciscon, E.; Zille, A.; Dias, G.F.; Ragagnin, M.C.; Durrant, L.R.; Cavaco-Paulo, A. Biodegradation of textile azo dyes by a facultative Staphylococcus arlettae strain VN-11 using a sequential microaerophilic/aerobic process. Int. Biodeterior. Biodegrad. 2009, 63, 280-288.

52. Franciscon, E.; Zille, A.; Durrant, L.R.; Fantinatti, G.F.; Cavaco-Paulo, A. Microaerophilic-aerobic sequential decolourization/biodegradation of textile azo dyes by a facultative Klebsiella sp. strain VN-31. Process. Biochem. 2009, 44, 446-452.

53. Voordouw, G.; Niviere, V.; Ferris, F.G.; Fedorak, P.M.; Westlake, D.W.S. Distribution of hydrogenase genes in Desulfovibrio spp. and their use in identification of species from the oil field environment. Appl. Environ. Microbiol. 1990, 56, 3748-3754. 
54. Muyzer, G.; de Waal, E.C.; Uitterlinden, A.G. Profiling of complex microbial populations by denaturing gradient gel electrophoresis analysis of polymerase chain reaction-amplified genes coding for 16S rRNA. Appl. Environ. Microbiol. 1993, 59, 695-700.

55. Annuar, M.S.M.; Adnan, S.; Vikineswary, S.; Chisti, Y. Kinetics and energetics of azo dye decolorization by Pycnoporus sanguineus. Water Air Soil Poll. 2009, 202, 179-188.

56. Taha, M.; Adetutu, E.M.; Shahsavari, E.; Smith, A.T.; Ball, A.S. Azo and anthraquinone dye mixture decolourization at elevated temperature and concentration by a newly isolated thermophilic fungus, Thermomucor. indicae-seudaticae. J. Environ. Chem. Eng. 2014, 2, 415-423.

57. Chung, K.T.; Stevens, S.E. Degradation of azo dyes by environmental microorganisms and helminthes. Environ. Toxicol. Chem. 1993, 12, 2121-2132.

58. Hu, T.L. Degradation of azo dye RP $2 \mathrm{~B}$ by Pseudomonas luteola. Water Sci. Technol. 1998, 38, 299-306.

59. Phugare, S.S.; Kalyani, D.C.; Patil, A.V.; Jadhav, J.P. Textile dye degradation by bacterial consortium and subsequent toxicological analysis of dye and dye metabolites using cytotoxicity, genotoxicity and oxidative stress studies. J. Hazard. Mater. 2011, 186, 713-723.

60. Lourenco, N.D.; Novais, J.M.; Pinheiro, H.M. Reactive textile dye colour removal in a sequencing batch reactor. Water Sci. Technol. 2000, 42, 321-328.

61. Phugare, S.S.; Kalyani, D.C.; Surwase, S.N.; Jadhav, J.P. Ecofriendly degradation, decolorization and detoxification of textile effluent by a developed bacterial consortium. Ecotoxicol. Environ. Saf. 2011, 74, 1288-1296.

62. Pandey, A.; Singh, P.; Iyengar, L. Bacterial decolorization and degradation of azo dyes. Int. Biodeterior. Biodegrad. 2007, 59, 73-84.

63. Pearce, C.I.; Lloyd, J.R.; Guthrie, J.T. The removal of colour from textile wastewater using whole bacterial cells: A review. Dyes Pigm. 2003, 58, 179-196.

64. Kadpan, I.K.; Kargi, F.; McMullan, G.; Marchant, R. Effect of environmental conditions on biological decolorization of textile dyestuff by C. versicolor. Enzyme Microb. Technol. 2000, 26, 381-387.

65. Levine, W.G. Metabolism of azo dyes: Implication for detoxification and activation. Drug Metab. Rev. 1991, 23, 253-309.

66. Singh, P.; Sanghi, R.; Pandey, A.; Iyengar, L. Decolorization and partial degradation of monoazo dyes in sequential fixed-filmed anaerobic batch reactor (SFABR). Bioresour. Technol. 2007, 98, 2053-2056.

67. Telke, A.A.; Ghodake, G.S.; Kalyani, D.C.; Dhanve, R.S.; Govindwar, S.P. Biochemical characteristics of a textile dye degrading extracellular laccase from a Bacillus $s p$. ADR. Bioresour. Technol. 2011, 102, 1752-1756.

68. Telke, A.; Kadam, A.; Govindwar, S. Bacterial enzymes and their role in decolorization of azo dyes. In Microbial Degradation of Synthetic Dyes in Wastewaters; Singh, S.N., Eds.; Springer International Publishing: Basel, Switzerland, 2015; Volume XIV, pp. 149-168.

69. Zimmerman, T.; Kulla, H.G.; Leisinger, T. Properties of purified orange II azo reductase, the enzyme initiating azo dye degradation by Pseudomonas KF46. Eur. J. Biochem. 1982, 129, 197-203. 
70. Telke, A.; Kadam, A.; Jagtap, S.; Jadhav, J.; Govindwar, S. Biochemical characterization and potential for textile dye degradation of blue laccase from Aspergillus ochraceus NCIM-1146. Biotechnol. Bioprocess. Eng. 2010, 15, 696-703.

71. Balapure, K.; Bhatt, N.; Madamwar, D. Mineralization of reactive azo dyes present in simulated textile waste water using down flow microaerophilic fixed film bioreactor. Bioresour. Technol. 2015, 175C, 1-7.

72. Russ, R.; Rau, J.; Stolz, A. The function of cytoplasmic flavin reductases in the reduction of azo dyes by bacteria. Appl. Environ. Microbiol. 2000, 66, 1429-1434.

73. Chang, J.S.; Lin, C.Y. Decolorization kinetics of a recombinant Escheria. coli strain harboring azo dye decolorizing determinants from Rhodococcus sp. Biotechnol. Lett. 2001, 23, 631-636.

74. Saratale, R.G.; Saratale, G.D.; Chang, J.S.; Govindwar, S.P. Decolorization and biodegradation of reactive dyes and dye wastewater by a developed bacterial consortium. Biodegradation 2010, 21, 999-1015.

75. Guilhermino, L.; Diamantino, T.; Silva, M.C.; Soares, A.M. Acute toxicity test with Daphnia magna: An alternative to mammals in the prescreening of chemical toxicity. Ecotoxicol. Environ. Saf. 2000, 46, 357-362.

76. Villegas-Navarro, A.; González, M.C.R.; López, E.R.; Aguilar, R.D.; Marçal, W.S. Evaluation of Daphnia magna as an indicator of toxicity and treatment efficacy of textile wastewaters. Environ. Int. 1999, 25, 619-624.

(C) 2015 by the authors; licensee MDPI, Basel, Switzerland. This article is an open access article distributed under the terms and conditions of the Creative Commons Attribution license (http://creativecommons.org/licenses/by/4.0/). 